NBER WORKING PAPER SERIES

PATENTS AND CUMULATIVE INNOVATION:
CAUSAL EVIDENCE FROM THE COURTS

\author{
Alberto Galasso \\ Mark Schankerman \\ Working Paper 20269 \\ http://www.nber.org/papers/w20269
NATIONAL BUREAU OF ECONOMIC RESEARCH
1050 Massachusetts Avenue
Cambridge, MA 02138
June 2014

We benefitted from comments by Alfonso Gambardella, John Golden, Dietmar Harhoff, Emeric Henry, Nicola Lacetera, Bhaven Sampat, David Schwartz, Carlos Serrano, Scott Stern, John Turner and Heidi Williams. Finally we thank seminar participants at the NBER 2013 Summer Institute, Ben Gurion University, Hebrew University of Jerusalem, Northwestern University, Tel Aviv University, UC Berkeley, University of Toronto, University of Texas at Austin, Tilburg University, Hitotsubashi University, University of Waterloo and Mines ParisTech. Deepa Agarwal, Faryal Ahmed, William Matcham and Jessica Zurawicki provided excellent research assistance. We are grateful for financial support from the Centre for Economic Policy at the London School of Economics and the Social Sciences and Humanities Research Council of Canada. The views expressed herein are those of the authors and do not necessarily reflect the views of the National Bureau of Economic Research.

NBER working papers are circulated for discussion and comment purposes. They have not been peerreviewed or been subject to the review by the NBER Board of Directors that accompanies official NBER publications.

(C) 2014 by Alberto Galasso and Mark Schankerman. All rights reserved. Short sections of text, not to exceed two paragraphs, may be quoted without explicit permission provided that full credit, including (C) notice, is given to the source. 
Patents and Cumulative Innovation: Causal Evidence from the Courts

Alberto Galasso and Mark Schankerman

NBER Working Paper No. 20269

June 2014

JEL No. O33,O34

\begin{abstract}
$\underline{\text { ABSTRACT }}$
Cumulative innovation is central to economic growth. Do patent rights facilitate or impede follow-on innovation? We study the causal effect of removing patent rights by court invalidation on subsequent research related to the focal patent, as measured by later citations. We exploit random allocation of judges at the U.S. Court of Appeals for the Federal Circuit to control for endogeneity of patent invalidation. Patent invalidation leads to a 50 percent increase in citations to the focal patent, on average, but the impact is heterogeneous and depends on characteristics of the bargaining environment. Patent rights block downstream innovation in computers, electronics and medical instruments, but not in drugs, chemicals or mechanical technologies. Moreover, the effect is entirely driven by invalidation of patents owned by large patentees that triggers more follow-on innovation by small firms.
\end{abstract}

\author{
Alberto Galasso \\ Rotman School of Management \\ University of Toronto \\ 105 St. George Street \\ Toronto, ON M5S 3E6 \\ Canada \\ and NBER \\ alberto.galasso@rotman.utoronto.ca \\ Mark Schankerman \\ Department of Economics, R.516 \\ London School of Economics \\ Houghton Street \\ London WC2A 2AE \\ UK \\ M.Schankerman@1se.ac.uk
}




\section{Introduction}

Cumulative research is a dominant feature of modern innovation. New genetically modified crops, computers, memory chips, medical instruments and many other modern innovations are typically enhancements of prior generations of related technologies. Of course, cumulative innovation is not new. Economic historians have emphasized the role of path dependence in the development of technology, documenting how past successes and failures serve as 'focusing devices' that guide the direction of later technological inquiry (Rosenberg, 1976). ${ }^{1}$ However, the increasing importance of basic science in shaping the direction of technological development has intensified this process.

Cumulative innovation, and the knowledge spillovers that underpin it, lie at the heart of the recent macroeconomic theory literature on innovation and growth. Leading examples of these endogenous growth models include Grossman and Helpman (1991), Aghion and Howitt (1992) and Acemoglu and Akcigit (2012). At the same time, there is an extensive empirical literature showing that $R \& D$ creates knowledge spillovers, which increase both productivity growth and subsequent innovation. ${ }^{2}$ This consensus on the centrality of knowledge spillovers to innovation, and innovation to growth, is the primary justification for government R\&Dsupport policies.

In this paper we study how patent rights affect the process of cumulative innovation. The patent system is one of the main instruments governments use to increase R\&D incentives, while at the same time promoting follow-on innovation. ${ }^{3}$ However, there is growing concern among academic scholars and policy makers that patent rights are themselves becoming an impediment, rather than an incentive, to innovation. The increasing proliferation of patents, and the fragmentation of ownership among firms, are believed to raise transaction costs, con-

\footnotetext{
${ }^{1}$ This cumulative feature is reinforced by the constraints imposed by the prevailing stock of scientific knowledge on the feasible avenues for technology development (Mokyr, 2002). This is not say that science dictates only one path for the development of technology at any point in time. Recent theoretical work emphasizes the role of diverse research approaches in technological development (Acemoglu, 2012).

${ }^{2}$ In a recent paper, Bloom, Schankerman and Van Reenen (2013) show that R\&D also creates negative (pecuniary) externalities through product market rivalry which can lead to over-investment in R\&D. But their empirical results confirm that positive externalities dominate, with social returns to $R \& D$ exceeding private returns, at least on average.

${ }^{3}$ Specifically, the disclosure provision in patent law (35 U.S.C. Section 112) requires the patent applicant to describe the invention in order to promote information diffusion and 'enable' development of follow-on improvements of the original invention.
} 
strain the freedom of action to conduct $R \& D$, and expose firms to ex-post holdup through patent litigation (Heller and Eisenberg, 1998; Bessen and Maskin, 2009). In the extreme case where bargaining failure in patent licensing occurs, follow-on innovation can be blocked entirely. These issues are particularly acute in 'complex technology' industries where innovation is highly cumulative and requires the input of a large number of patented components held by diverse firms. These dangers have been prominently voiced in public debates on patent policy in the United States (Federal Trade Commission, 2011) and recent decisions by the Supreme Court (e.g., eBay Inc. v. MercExchange, L.L.C., 547 U.S. 338, 2006).

Economic research on the impact of patent rights on cumulative innovation has been primarily theoretical. The main conclusion from these studies is that anything can happen patent rights may impede, have no effect, or even facilitate subsequent technological development. It depends critically on assumptions about the bargaining environment and contracting efficiency between different generations of innovators. In an early contribution, Kitch (1977) argues that patents enable an upstream inventor to coordinate investment in follow-on innovation more efficiently and to mitigate rent dissipation from downstream patent races that would otherwise ensue. This 'prospecting theory' suggests that patent rights facilitate cumulative innovation. In contrast, Green and Scotchmer (1995) show that upstream patent rights will not impede value-enhancing, follow-on innovation as long as bargaining between the parties is efficient. This work is important because it focuses our attention on bargaining failure as the source of any blocking effect patent rights might create. Finally, a number of papers have shown how patent rights can block innovation when bargaining failure occurs. This can arise from asymmetric information (Bessen and Maskin, 2009), or coordination failures when downstream innovators need to license multiple upstream patents (Galasso and Schankerman, 2010).

This diversity of theoretical models highlights the need for empirical research. It is important not only to establish whether patent rights block subsequent innovation, but also to identify how this effect depends on the characteristics of the bargaining environment and the transacting parties. These issues are central to an understanding on how patent rights affect the dynamics of the 'industrial organization' of innovation.

There are two empirical challenges in studying the effect of patents on cumulative innovation. First, cumulativeness is difficult to measure directly. In this paper we primarily follow the large empirical literature that uses citations by later patents as a way to trace knowl- 
edge spillovers (for a survey, see Griliches, 1992). While not perfect, this is the only feasible approach if one wants to study the impact of patent rights across diverse technology fields as we do in this paper. Nonetheless, we also show that our results are robust to alternative measures of cumulative innovation in the technology fields of drugs and medical instruments, where data on new product developments are publicly available due to government regulation that requires public registration. The second problem in identifying the causal effect of patent rights on later innovation is the endogeneity of patent protection. For example, technologies with greater commercial potential are both more likely to be protected by patents and to be an attractive target for follow-on innovation.

Given the importance of the issue, there is surprisingly little econometric evidence on the link between patent rights and cumulative innovation. In two influential papers, Murray and Stern (2007) and Williams (2013) provide the first causal evidence that intellectual property rights block later research in the biomedical field. Murray and Stern exploit patent-paper pairs to study how citations to scientific papers are affected when a patent is granted on the associated invention. Williams studies the impact of intellectual property on genes sequenced by the private firm Celera on subsequent human genome research and product development. Interestingly, both papers find roughly similar magnitudes - property rights appear to cause about a 20-40 percent reduction in follow-on research. These important studies focus on very specific (albeit significant) innovations in human genome and biomedical research. It is hard to know whether their conclusions generalize to other industries, and whether the effect varies across different types of patentees and later innovators. Understanding how the blocking effect of patents varies across technology fields and patent owners is essential for thinking about how best to design the strength and scope of patent protection.

In this paper we adopt a novel identification strategy to estimate the causal effect of patent protection on cumulative innovation. We use the patent invalidity decisions of the U.S. Court of Appeal for the Federal Circuit, which was established in 1982 and has exclusive jurisdiction in appellate cases involving patents. It is a fortunate institutional fact that judges are assigned to patent cases through a computer program that randomly generates three-judge panels, with decisions governed by majority rule. We exploit this random allocation of judges, together with variation in their propensity to invalidate patents, to construct an instrumental variable which addresses the potential endogeneity of invalidity decisions. Because patents 
constitute prior art, later applicants are still required to cite patents when relevant even if they have been invalidated and thus put into the public domain. This allows us to examine how invalidation of a patent affects the rate of subsequent citations to that patent.

Patents that reach the Federal Circuit are a selective sample of highly valuable patents. To cite one example, in August 2006 the Federal Circuit invalidated one of Pfizer's key patents required for the production of the cholesterol-lowering drug Lipitor, the largest-selling drug in the world. Our reliance on privately valuable patents to estimate the effect of patent rights on cumulative innovation is similar to Azoulay, Graff Zivin and Wang (2007) who rely on the death of superstar scientists to estimate the magnitude of knowledge spillovers. It is reasonable to start by analyzing high value patents rather than a random sample of patents, not least because we know that the distribution of patent values is highly skewed (Schankerman and Pakes, 1986) and policy should be most concerned about the potential blocking of later innovation that builds on these valuable patents, where the potential welfare costs are likely to be larger.

There are three main empirical findings in the paper. First, we show that patent invalidation leads to about a 50 percent increase in subsequent citations to the focal patent, on average and that this finding is robust to a wide variety of alternative specifications and controls. Moreover, we show that this impact begins only after two years following the court decision, which is consistent with the entry of new downstream innovators, but is not consistent with the alternative explanation that the increase in citations is simply driven by a publicity effect from the court's decision.

Second, we find that the impact of patent invalidation on subsequent innovation is highly heterogeneous. For most patents, the marginal treatment effect of invalidation is not statistically different from zero. The positive impact of invalidation on citations is concentrated on a small subset of patents which have unobservable characteristics that are associated with a lower probability of invalidity (i.e., stronger patents). There is also large variation across broad technology fields in the impact of patent invalidation and the effect is concentrated in fields that are characterized by two features: complex technology and high fragmentation of patent ownership. This finding is consistent with predictions of the theoretical models that emphasize bargaining failure in licensing as the source of blockage. Patent invalidation has a significant impact on cumulative innovation only in the fields of computers and communications, electronics, and medical instruments (including biotechnology). We find no effect for drugs, chemicals, 
or mechanical technologies. Moreover, for two of the technology fields we study - medical instruments and drugs - we are able to construct alternative measures of cumulative innovation that exploit data on publicly-disclosed new product developments. The results confirm our findings using citations: patent invalidation has a significant effect on later innovation in medical instruments but no effect in pharmaceuticals.

Lastly, we show that the effect of patent rights on later innovation depends critically on the characteristics of the transacting parties. The impact is entirely driven by the invalidation of patents owned by large firms, which increases the number of small innovators subsequently citing the focal patent. We find no statistically significant effect of patent rights on later citations when the invalidated patents are owned by small or medium sized firms. This result suggests that bargaining failure between upstream and downstream innovators is not widespread, but is concentrated in cases involving large patentees and small downstream innovators.

Taken together, our findings indicate that patent rights block cumulative innovation only in very specific environments and this suggests that government policies should be targeted at facilitating more efficient licensing in those environments. However, we want to emphasize that the 'experiment' in this paper involves the judicial removal of an existing patent right. In Section 8 we discuss some of the conceptual differences between our setting and an alternative thought experiment in which patent rights are not granted in the first place. We will argue that these two regimes differ in term of the underlying incentives for the rate and direction of innovation, and in the capability of patents to serve as an informational signal that facilitates access to capital markets, especially for small firms.

The paper is organized as follows. In Section 2 we present a simple model that characterizes conditions under which patents facilitate, block or have no effect on follow-on innovation. The model highlights the key role of bargaining failure between upstream and downstream innovators, and coordination failure among competing downstream innovators. Section 3 describes the data set. In Section 4 we develop the baseline econometric model for estimating the causal effect of patent rights and present the empirical results. In Section 5 we extend the analysis to allow for heterogenous marginal treatment effects, and empirically link them to characteristics of the patent case. Section 6 shows how the effect of patent invalidation depends on the characteristics of the patentee and later citing innovators. In addition, we decompose the overall effect into an extensive margin (number of later citing firms) and an intensive mar- 
gin (number of later citing patents per firm). Section 7 examines the robustness of our findings to using measures of downstream innovation that do not depend on patent citations. Section 8 discusses the interpretation and implications of the empirical findings. We conclude with a brief summary of findings. Details of data construction and extensive robustness analysis are included in a set of (online) Appendices.

\section{Analytical Framework}

The granting of patent rights involves a basic trade-off between ex ante incentives and ex post efficiency. The market power conferred by a patent increases innovation incentives, but also reduces total surplus due to higher prices. This trade-off is well understood in the innovation literature. However, patents can also create a dynamic cost by blocking valuable sequential innovation, in cases where a second generation firm requires a license on the earlier technology and the bargaining between the two parties fails. In this section we present a simple analytical framework that characterizes conditions under which patents are likely to block, facilitate or have no effect, on follow-on investment, and we use the framework to organize the different theoretical models in the literature. The key feature in our framework is a trade-off between bargaining failure due to asymmetric information, which impedes licensing when there is an upstream patent, and coordination failure among downstream innovators which reduces their incentives to invest in the absence of patent rights.

There is one upstream technology, and one potential downstream innovation. The value of the downstream technology can be high or low, which we denote by $\lambda \in\{\underline{\lambda}, \bar{\lambda}\}$ with $\underline{\lambda}<\bar{\lambda}$. There are two identical potential downstream inventors. To develop the follow-on technology an innovator needs to sustain a cost equal to $S$. We make the following assumptions:

Assumption 1: Downstream innovators know the value of the follow-on technology. The owner of the upstream technology assigns probability $\operatorname{Pr}(\lambda=\bar{\lambda})=\alpha$ that the downstream technology has high value.

Assumption 2: $\lambda / 2-S<0$ for $\lambda \in\{\underline{\lambda}, \bar{\lambda}\}$.

As in Galasso and Schankerman (2010), Assumption 1 generates an asymmetric information problem by restricting the knowledge of the upstream patentee on the value of the downstream innovation. Assumption 2 creates a coordination problem by making it unprof- 
itable for both downstream innovators to invest, as in Bolton and Farrell (1990). We contrast the case in which the upstream technology is not patented and the case in which there is patent protection. The crucial difference between the two cases is that without a patent on the upstream technology the follow-on innovators can freely decide whether to invest in downstream innovation. In contrast, with patent protection on the upstream technology, a licensing deal is required.

\section{No patent on the upstream technology}

In the absence of upstream protection, each of the follow-on innovators chooses independently whether to invest or not. We assume that in the absence of investment an innovator obtains a payoff equal to 0 . If the innovator is the only one to develop the follow-on innovation, the payoff of the innovator is $\lambda-S>0$ with $\lambda \in\{\underline{\lambda}, \bar{\lambda}\}$. This payoff captures the idea that the follow-on innovator is the patentee of the second generation technology and appropriates the entire value. We assume that, if both innovators invest, each of them obtains the patent with probability $1 / 2$ so their expected payoffs will be $\lambda / 2-S<0$ with $\lambda \in\{\underline{\lambda}, \bar{\lambda}\}$.

There are two asymmetric pure strategies Nash equilibria in which one of the two followon innovators invests and the other does not invest. The literature on economic coordination suggests that these asymmetric pure-strategy equilibria are unconvincing in a symmetric setting like ours. For example, Crawford and Haller (1990) formally show that it is inappropriate to focus on asymmetric pure-strategy equilibria because it is not clear how players find one of those equilibria. Therefore, we follow Bolton and Farrell (1990) and focus on the symmetric mixed strategy equilibrium. Each innovator invests with probability $p(\lambda)=2(\lambda-S) / \lambda$ with $\lambda \in\{\underline{\lambda}, \bar{\lambda}\}$. This implies that follow-on innovation takes place with probability $1-(1-p(\bar{\lambda}))^{2}$ if the second generation technology has high value, and probability $1-(1-p(\underline{\lambda}))^{2}$ if the downstream technology has low value. Thus the expected level of follow-on innovation is

$$
I_{N O P}=\alpha\left(1-\left(\frac{2 S-\bar{\lambda}}{\bar{\lambda}}\right)^{2}\right)+(1-\alpha)\left(1-\left(\frac{2 S-\underline{\lambda}}{\underline{\lambda}}\right)^{2}\right)
$$

\section{Patent on the upstream technology}

If the upstream technology is protected by a patent, the patentee can potentially block downstream innovation. Patentability of the follow-on technology induces the owner of the base technology to license it to only one of the two downstream innovators. We assume that the 
patentee makes a take-it-or-leave it offer to the follow-on innovator. ${ }^{4}$ A licensing fee equal to $\underline{\lambda}-S$ will be accepted both when the value of the downstream innovation is high as well as when the value is low. A fee equal to $\bar{\lambda}-S$ will be accepted only when the second generation technology has high value. Notice that in expectation it is more profitable to offer $\bar{\lambda}-S$ if $\alpha(\bar{\lambda}-S) \geq \underline{\lambda}-S$, i.e. when $\alpha \geq \widehat{\alpha} \equiv(\underline{\lambda}-S) /(\bar{\lambda}-S)$.

This implies that, with patent protection on the upstream technology, the expected level of downstream innovation occurs is

$$
I_{P}=\left\{\begin{array}{c}
1 \text { if } \alpha \leq \widehat{\alpha} \\
\alpha \text { if } \alpha>\widehat{\alpha}
\end{array}\right.
$$

\section{Comparison of the two regimes}

Proposition 1 compares the expected level of downstream innovation with and without patent rights on the upstream technology.

Proposition 1 For $\bar{\lambda}$ large enough there exists $\alpha^{\prime}>\widehat{\alpha}$ such that $I_{N O P}>I_{P}$ if $\widehat{\alpha}<\alpha<\alpha^{\prime}$ and $I_{P}>I_{N O P}$ if $\alpha>\alpha^{\prime}$ or $\alpha<\widehat{\alpha}$.

Proof. The expected level of follow-on innovation without patent protection on the base technology (1) increases linearly in $\alpha$. For $\alpha=1$ we have that $I_{N O P}=1-\left(\frac{2 S-\bar{\lambda}}{\bar{\lambda}}\right)^{2}<1=I_{P}$. For $\alpha=0$ we have $I_{N O P}=1-\left(\frac{2 S-\underline{\lambda}}{\underline{\underline{\lambda}}}\right)^{2}<1=I_{P}$. Continuity of $(1)$ implies that $I_{P}>I_{N O P}$ for values of $\alpha$ close to zero and one. Now consider the innovation activity at $\widehat{\alpha}$. At this value $I_{N O P} \geq I_{P}$ if

$$
\frac{\underline{\bar{\lambda}}-S}{\bar{\lambda}-S}\left(1-\left(\frac{2 S-\bar{\lambda}}{\bar{\lambda}}\right)^{2}\right)+\left(1-\frac{\lambda-S}{\bar{\lambda}-S}\right)\left(1-\left(\frac{2 S-\underline{\lambda}}{\underline{\lambda}}\right)^{2}\right)>\frac{\lambda}{\bar{\lambda}-S}
$$

that is satisfied for $\bar{\lambda}$ large enough (i.e. close enough to $2 S$ ). Finally, continuity of (1) and the fact that $I_{N O P}<I_{P}$ when $\alpha=1$ implies that there exists a $\alpha^{\prime}$ at which $I_{P}=I_{N O P}$.

The proposition shows that the impact of upstream patent rights on follow-on innovation depends critically on the trade-off between coordination failure and bargaining breakdown. Figure 1 illustrates the result. Intuitively, patent protection is not associated with low followon innovation for values of $\alpha$ that are high or low. This is because, when $\alpha$ is close to zero

\footnotetext{
${ }^{4}$ Following the literature on decentralization, we assume that the patentee can only make one offer and that he cannot implement more sophisticated mechanisms, as in Cremer and McLean (1985), to extract information from the follow-on innovators.
} 
or one, uncertainty about the value of follow-on innovation is low and the patentee can offer a profitable licensing fee that is accepted with high probability by the follow-on innovator. For intermediate values of $\alpha$, there is greater uncertainty about the value of the follow-on innovation and the likelihood of bargaining failure is more severe.

In the absence of upstream patent rights, bargaining failure plays no role since the downstream innovator does not need a license to use the upstream technology. However, the absence of downstream coordination reduces the incentives for each follow-on innovator to invest. ${ }^{5}$ When the technology is highly profitable $(\bar{\lambda}$ large $)$, coordination failure is less costly and follow-on innovation becomes more likely. This implies that the absence of upstream patent rights can generate either a higher or lower level of downstream innovation than a regime with upstream patent protection.

\section{Relation with previous literature}

Our model shows that the impact of upstream patent rights on follow-on innovation depends on the relative strength of coordination and bargaining failure in licensing negotiations. We can generate the different predictions of various models in the innovation literature by relaxing one or both of the two key assumptions in our model.

If we drop Assumption 1, so both downstream and upstream innovators know the value of the follow-on technology, there is no bargaining failure and our model predicts higher followon innovation when there is an upstream patent. This prediction is in line with Kitch (1977), who describes an environment in which, in the absence of an upstream patent, development of technology improvements is impeded by coordination failure and free riding among downstream innovators. A patent on the base technology allows the upstream firm to act as a gatekeeper to coordinate downstream investments.

By dropping Assumption 2 and allowing $\lambda / 2-S>0$ for $\lambda \in\{\underline{\lambda}, \bar{\lambda}\}$, we turn off coordination failure and our model implies that an upstream patent reduces follow-on innovation. This prediction is consistent with models where ex ante licensing does not take place in the presence of asymmetric information, as in Bessen and Maskin (2009). But licensing breakdown can also arise for other reasons. Galasso (2012) shows that licensing breakdown may occur even

\footnotetext{
${ }^{5}$ It also generates a positive probability of duplicative investment. Whether such duplication has a positive or negative impact on overall welfare depends on the relationship between $\lambda$ and consumer welfare.
} 
with symmetric information when parties have divergent expectations about the profitability of the technology. The risk of hold up, high litigation costs and pro-patent remedy rules all reduce the expected value of ex post licensing profits for the downstream innovator and thus dilute her incentives to develop the new technology. Bargaining failure can also arise when patent ownership is fragmented and a downstream firm requires licenses from many different patentees to conduct its research. In this case, uncoordinated bargaining among the parties leads to 'royalty stacking' that reduces the licensee's profit and, in extreme cases, can actually block downstream development (Heller and Eisenberg, 1998; Lemley and Shapiro, 2007; Galasso and Schankerman, 2010).

Finally, dropping both Assumptions 1 and 2, we obtain a framework similar to Green and Scotchmer (1995) in which ex ante contracting guarantees that any joint surplus enhancing downstream innovation is developed independently of the presence of a patent on the base technology. In their model the length and breadth of upstream patent rights affect the profitability and thus the incentive to develop the upstream technology, but once it is developed, frictionless bargaining ensures that efficient downstream investment takes place. ${ }^{6}$

\section{Description of the Data}

The empirical work is based on two data sets: the decisions of the Court of Appeal for the Federal Circuit, and the U.S. Patent and Trademark Office (USPTO) patent dataset.

The Federal Circuit was established by the U.S. Congress on October 1, 1982 and has exclusive jurisdiction over appeals in cases involving patents and claims against the federal government in a variety of subject matter. The Federal Circuit consists of twelve judges appointed for life by the president. Judges are assigned to patent cases through a computer program that randomly generates three-judge panels, subject to their availability and the requirement that each judge deals with a representative cross section of the fields of law within the jurisdiction of the court (Fed. Cir. R. 47.2). Decisions are taken by majority rule. We obtain the full text of patent decisions by the Federal Circuit from the LexisNexis QuickLaw dataset. This contains a detailed description of the litigated dispute, the final decision reached by the court, and the jurisprudence used to reach the decision. Using keyword searches, we identify each case

\footnotetext{
${ }^{6}$ Even though blockage does not occur in this framework, Koo and Wright (2010) show that patent rights can induce the downstream innovator to delay development.
} 
involving issues of patent validity from the establishment of the court in 1982 until December 2008. For each case we record the following information: docket number, date of the decision, patent identification number, name of the three judges involved, name of the plaintiff, name of the defendant, and whether the patentee is the plaintiff or the defendant. ${ }^{7}$

Information about each patent in the sample is obtained from the USPTO patent database. We also identified the patents citing the litigated patent from two sources: the USPTO citations data for sample patents granted in the period 1975-2010, and Google Patents for sample patents granted before 1975 .

We use the number of citations by subsequent patents to the focal patent as a measure of cumulative innovation. Patent applicants are required to disclose known prior art that might affect the patentability of any claim (Code of Federal Regulations, Ch. 37, Section 1.36), and any willful violation of this duty can lead to the USPTO rendering the patent unenforceable due to 'inequitable conduct'. Importantly for our purposes, the expiration or invalidation of a patent has no impact on its prior art status (35 U.S. Code, Section 102), so the requirement to cite it remains in place. Citations have been widely used in the economics of innovation literature as a proxy for follow-on research and are the only practical measure of cumulative innovation for studies such as ours that cover a wide range of technology fields. In Section 7 we further discuss the merits of citations as a measure of follow-on innovation and we also show that our results are robust to alternative measures of cumulative innovation that we can construct for two technology fields, drugs and medical instruments.

The main variables used in the empirical analysis are described below.

PostCites: citations received from patents of other assignees (owners) in a five year window after the Federal Circuit decision. This is our primary measure of cumulative innovation. Because of granting delays, we date the citing patents using their application year rather than grant year.

PostTotalCites: citations received both from patents owned by the same patentee as the focal patent and patents of other assignees in a five year window after the Federal Circuit decision.

Invalidated: a dummy variable equal to one if the Federal Circuit invalidates at least

\footnotetext{
${ }^{7}$ Under very special circustances judges or the litigating parties may petition to have the case decided "en banc" by all the judges of the court. These very few cases are dropped from our sample.
} 
one claim of the patent. This is the main explanatory variable of interest, and represents the removal of patent rights. ${ }^{8}$

PreCites: citations received from patents of other assignees applied for in the period between the grant of the patent and the Federal Circuit decision

PreSelfCites: citations received from patents of the same patentee as the focal patent applied for in the period between the grant of the patent and the Federal Circuit decision

Claims: total number of claims listed in the patent document

Technology field: dummy variables for the six technology classes in Hall, Jaffe and Tratjenberg (2001) - chemicals, computers and communications, drugs and medical, electrical and electronics, mechanicals, and others. We will also employ a narrower definition based on the 36 two-digit subcategories.

Finally, we construct a set of dummy variables for the year when the Federal Circuit decision is issued and for the age of the patent. The final dataset contains 1357 Federal Circuit patent validity decisions, covering 1258 distinct patents. ${ }^{9}$ Table 1 provides some summary statistics. The Federal Circuit invalidates in 39 percent of the cases. There is substantial variation in the age distribution of litigated patents at the time of the Federal Circuit decision (see Figure A1 in the Appendix). Note that lengthy lower court trials in some cases lead to Federal Circuit decisions occurring after the patent has expired.

Patents involved in Federal Circuit cases are a selected sample of highly valuable patents. For example, in January 2005 the Federal Circuit invalidated the patent for the once-a-week version of Merck's Fosamax, the leading osteoporosis drug in the market at that time. This can be seen in Table 2, which compares characteristics of the patents in the Federal Circuit to patents litigated in lower courts but not appealed, as well as to the universe of patents granted by the USPTO. Drugs and medical instruments patents are more heavily represented in the litigated and Federal Circuit samples than in the overall sample. This is consistent with survey evidence that patent rights are most important in that sector (Levin et. al., 1987). We also see

\footnotetext{
${ }^{8}$ We experimented with an alternative definition of invalidation as whenever claim 1 of the patent (typically representing the primary claim) is invalidated. About 40 percent of patents are invalidated on our baseline measure, and 33 percent using the alternative definition. The empirical results are very similar with both measures.

${ }^{9}$ This is because there are multi-patent cases and some patents are litigated more than once. Our sample size
and mean invalidation rate are similar to an earlier study using Federal Circuit cases (Henry and Turner, 2006).
} 
that commonly used indicators of patent value - the number of claims, citations per claim, and measures of patent generality and originality (as defined by Hall, Jaffe and Tratjenberg, 2001) are all higher for litigated than other patents, and even higher for cases appealed to the Federal Circuit. ${ }^{10}$ Equality of the means is strongly rejected for all four variables (p-values $\left.<0.01\right)$. The mean number of claims and citations per claim for patents litigated only at lower courts are different from those appealed to the Federal Circuit ( $p$-values $<0.01)$.

While self-selection of patents through the appeals process is certainly related to the private value of patents, other factors may play a role. First, cases with greater legal complexity are more likely to reach appeal because settlement by the parties is harder due to divergent expectations about how the court would decide the legal issues. Second, patents with greater technological scope for follow-on innovation are more likely to be involved in litigation in the first place. For both reasons, invalidation of patents in our sample is more likely to be associated with an increase in follow-on innovation than for the population of patents as a whole.

\section{Estimating the Impact of Patent Rights}

\section{Baseline Specification and Identification Strategy}

The final dataset is a cross section where the unit of observation is a Federal Circuit case involving patent $p .{ }^{11}$ Our main empirical specification is

$$
\begin{gathered}
\log \left(\text { PostCites }_{p}+1\right)=\beta \text { Invalidated }_{p}+\lambda_{1} \log \left(\text { PreCites }_{p}+1\right) \\
+\lambda_{2} \log \left(\text { PreSelfCites }_{p}+1\right)+\lambda_{3} \log \left(\text { Claims }_{p}\right)+\text { Age }_{p}+\text { Year }_{p}+\text { Tech }_{p}+\varepsilon_{p}
\end{gathered}
$$

The coefficient $\beta$ captures the effect of invalidation on the subsequent (non-self) citations received by a patent. When $\beta<0$ invalidation reduces later citations, indicating that patent rights have a positive impact on cumulative innovation. A finding of $\beta=0$ would indicate that patents do not block follow-on innovation. When $\beta>0$ we would conclude that patents block subsequent innovation. ${ }^{12}$

\footnotetext{
${ }^{10}$ Generality is defined as one minus the Herfindahl index of the citations received by a patent across different technology classes. Originality is defined the same way, except that it refers to citations made.

${ }^{11}$ Even though we have some cases of the same patent litigated more than once, we use the subscript $p$ to denote the patent case to emphazise that our sample is a cross section.

${ }^{12}$ While a variety of econometric models can be used to estimate the correlation between citations and the Federal Circuit invalidity decisions, the cross-sectional specification is preferable for two reasons. First, it allows
} 
To control for heterogeneity in the value that the patent has for the patentee and follow on inventors, we include the number of claims and the number of external and self citations received prior to the Federal Circuit decision (PreCites and PreSelfCites, respectively) as covariates in the regression. We also include age, decision year and technology field dummies to control for additional heterogeneity that may be correlated with the court decision and later citations. We report heteroskedasticity-robust standard errors. Because some patents are litigated more than once and some cases involve multiple patents, we also confirm significance using standard errors clustered at the patent or case level.

The major empirical challenge is that the decision by the Federal Circuit to invalidate a patent is endogenous. For example, a positive shock to the value of the underlying technology may increase citations to a patent and, at the same time, induce the patentee to invest heavily in the case to avoid invalidation. This would generate a negative correlation between $\varepsilon_{p}$ and Invalidated $_{p}$ in equation (3) and a downward bias to the OLS estimate of $\beta$. To address potential endogeneity, we need an instrument that affects the likelihood of patent invalidation but does not belong directly in the citations equation.

To construct such an instrument, we exploit the fact that judges in the Federal Circuit are assigned to patent cases randomly by a computer program, subject to their availability and the requirement that each judge deals with a representative cross section of legal fields within the court's jurisdiction (Fed. Cir. R. 47.2). The Federal Circuit patent cases in our sample have involved a total of 51 distinct judges, including 22 non-appointed judges that filled in the vacancies during the Senate nomination process. There is substantial variation across judges in the propensity to vote for patent invalidity (which we refer to as judge 'bias'), ranging from a low of 24.4 percent to a high of 76.2 percent. ${ }^{13}$ This fact, together with the randomization of judge panels, creates exogenous variation in patent invalidation. However, it does not ensure randomization of decisions, which could still arise because of information

us to use our time invariant allocation of judge panels as an instrument for patent invalidity decisions. Second, this specification allows us to examine heterogeneity in the effect of patent invalidation by estimating the Marginal Treatment Effect. Our approach is similar to other studies where cross sectional instrumental variables are used to examine heterogeneous causal effects (e.g., Carneiro, Heckman and Vytlacil, 2010).

\footnotetext{
${ }^{13}$ In Appendix Table A1 we list the (appointed) Federal Circuit judges in our sample, the number of decisions in which each judge was involved, and the percentage of cases in which each judge voted for patent invalidation. We use the term 'bias' to refer to variation across judges in their propensity to invalidate, but it can also reflect differences in their expertise and ability to process information in the different technology fields covered by the patent cases.
} 
that becomes available during the appellate process that could also be correlated with future citations. The instrument we construct also takes this concern into account.

Our instrumental variable, the Judges Invalidity Propensity $(J I P)$, is defined for each case involving patent $p$ as

$$
J I P_{p}=f_{p}^{1} f_{p}^{2} f_{p}^{3}+f_{p}^{1} f_{p}^{2}\left(1-f_{p}^{3}\right)+f_{p}^{1}\left(1-f_{p}^{2}\right) f_{p}^{3}+\left(1-f_{p}^{1}\right) f_{p}^{2} f_{p}^{3}
$$

where $f_{p}^{1}, f_{p}^{2}, f_{p}^{3}$ are the fractions of votes in favour of invalidity by each of the three judges assigned to the case calculated for all decisions excluding the case involving patent $p$. In other words, the decision for the focal patent does not enter into the computation of the instrument for that decision. In a simple setting where each judge $i$ votes in favor of invalidity with probability $f_{p}^{i}, J I P$ captures the probability of invalidation by the three judge panel (decision by majority rule). In Appendix 1 we show that, under plausible assumptions on the dispersion of private information, JIP provides a consistent estimate of the probability of invalidation in a strategic voting model (based on Feddersen and Pesendorfer, 1996) where the thresholds of reasonable doubt differ across judges.

There are two important features of JIP that make it a valid instrumental variable. First, the random allocation of judges assures that judges with high propensity to invalidate are not assigned to cases because of unobservable characteristics that are correlated with citations. Second, any additional effect that case-specific unobservables may have on the decision to invalidate patent $p$ (e.g., information revealed during the litigation process) is removed by dropping the decision on patent $p$ from the construction of the instrument for patent $p .^{14} 15$ There is substantial variation in the distribution of the JIP index (mean of 0.34 , range from 0.16 to 0.58$)$. About 11 percent of the variation in JIP reflects year effects, because 'biased' judges may be active only for a limited period of time.

Our identification strategy is similar to the one employed by Kling (2006), who uses ran-

\footnotetext{
${ }^{14}$ Settlement at the appellate level is quite infrequent. Aggregate figures available on the Federal Circuit website show that in the period 1997-2007 about 80 percent of the filed cases were terminated with a panel decision. A possible reason for the low settlement rate is that the identity of judges is revealed to the disputants only after all briefs have been filed, and most of legal costs have already been sunk.

${ }^{15}$ A natural alternative to $J I P$ is to use judge fixed effects. There are two reasons why JIP is preferred. First, JIP takes into account that the invalidity decision is taken by a panel of judges, so the impact of each judge's invalidity propensity depends on the other members of the panel. Second, in JIP the dependence on the endogenous regressor for observation $i$ is removed by dropping that observation in the construction of the instrument (as in the Jackknife IV of Angrist et. al., 1999).
} 
dom assignment of judges to estimate the effects of incarceration on employment and earnings of individuals, and Doyle (2007, 2008) who uses differences in the placement tendency of child protection investigators to identify the effects of foster care on long term outcomes. ${ }^{16}$ The main difference between the two approaches is that our JIP index is constructed at the (three judge) panel level. The basic assumption behind our measure is that judges differ in their propensity to invalidate patents. To check this, we construct a dataset with judge-vote as the unit of observation and regress the Invalidated dummy against judge fixed effects and controls for the number of claims, external and self-citations prior to the court decision, plus decision year, technology class and patent age fixed effects. We strongly reject the hypothesis that the fixed effects for the different judges are the same (p-value $<0.01) .{ }^{17}$

Our main estimation approach, following Galasso, Schankerman and Serrano (2013), instruments the invalidated dummy with the predicted probability of invalidation obtained from the probit model $\widehat{P}=P(J I P, X)$. When the endogenous regressor is a dummy, this estimator is asymptotically efficient in the class of estimators where instruments are a function of JIP and other covariates (Wooldridge, 2002). Specifically, we estimate the following twostage model

$$
\begin{aligned}
\text { Invalidated }_{p} & =\alpha \widehat{P}_{p}+\theta X_{p}+u_{p} \\
\log \left(\text { PostCites }_{p}+1\right) & =\beta \text { Invalidated }_{p}+\gamma X_{p}+\varepsilon_{p} .
\end{aligned}
$$

where the set of controls $X$ is the same in both stages.

\section{Judge Panels and Patent Invalidation}

Table 3 examines the relationship between patent invalidation and the composition of judge panels. We begin in column 1 by using judge fixed effects to capture variation in judge 'bias'. Regressing Invalidity on these dummies and other controls, we strongly reject equality of judge

\footnotetext{
${ }^{16}$ Other recent papers that exploit heterogeneity in the decision of judges and other experts for identification include Li (2012), Dahl et. al. (2013), Di Tella and Schargrodsky (2013), Dobbie and Song (2013) and Maestas et. al. (2013).

${ }^{17}$ To provide additional evidence that the estimated variation is inconsistent with judges having identical voting propensities, we construct a counterfactual where judges vote according to the same random process (details are provided in Appendix 2). We use the simulated vote to estimate judge fixed effects and find that they are not statistically significant ( $p$-value=0.66). We also compare the distribution of these fixed effects from simulated votes with the (statistically significant) fixed effects estimated using actual voting behavior. The difference between the two distributions is striking: the variance of the Federal Circuit fixed effects is much larger than the one we would observe if judges were voting following the same random process.
} 
effects, confirming heterogeneity in the propensity to invalidate. The judge fixed effects explain about 6.5 percent of the variation in Federal Circuit invalidity decisions.

As indicated earlier, however, using judge fixed effects in our context neglects the fact that decisions are taken by three-judge panels. To take this into account, in columns 2 and 3 we report probit regression models of the invalidity dummy against the JIP index. The estimated marginal effect in column 2 indicates that a one standard deviation increase in JIP is associated with an increase of about 7 percentage points in the likelihood of invalidation. The results are similar when we add a set of controls for patent characteristics (column 3) a one standard deviation change in $J I P$ is associated with an increase of about 5 percentage points in the probability of invalidation (the implied elasticity is 1.07). We also find that the patents that are more heavily cited before the court decision are less likely to be invalidated. Interestingly, there are no significant differences across technology fields in the likelihood of invalidation (joint test has a $\mathrm{p}$-value $=0.17) .{ }^{18}$

Finally, in column 4 we present the result of an OLS regression with JIP as dependent variable that supports the randomization of judges to cases. The number of claims of the litigated patent, the pre-decision citations, the age of the patent and its technology class are all uncorrelated with the propensity of the judges to invalidate patents. Only the year effects are significantly correlated with $J I P$. The significance of the year effects arises mechanically because some of the 'biased' judges are active only for a fraction of our sample period. For additional evidence that judges are randomly assigned and $J I P$ is orthogonal to patent characteristics known prior to the decision, we examine the correlation between JIP and various subsets of the patent characteristics in our sample. In all cases the correlations are close to zero and statistically insignificant (see Appendix 2 for details).

We perform a variety of tests to confirm robustness of these findings (results not reported, for brevity). First, there is the concern that the invalidity decision may depend on whether patents have been invalidated by lower courts. To address this issue, we controlled for the lower court decision and find a positive correlation between the Federal Circuit and district court decisions. However, introducing this additional covariate has essentially no effect

\footnotetext{
${ }^{18}$ Results are robust to using an alternative measure of invalidation - the fraction of invalidated claims. We find a positive and statistically significant association between the degree of patent invalidation and the JIP index.
} 
on the magnitude and statistical significance of the JIP coefficient. Second, invalidity decisions may also depend on characteristics of technology sub-fields not captured by our six broad technology category dummies. We re-estimate the probit regression controlling for more detailed technology field classifications using the 32 NBER technology sub-categories. The magnitude of the estimated JIP coefficient remains similar $(1.262$, p-value $<0.01)$. In addition, we re-run the probit regression in column 3 separately for each of our six different technology fields. The magnitude and the statistical significance of the coefficients are very similar to the pooled data, indicating that the correlation between JIP and invalidity is comparable across technology classes. Finally, we obtained similar marginal effects using logit and linear probability models, and confirmed statistical significance using standard errors clustered at the patent or case level.

\section{Patent Invalidation and Cumulative Innovation}

\section{Baseline Specification}

In Table 4 we examine how patent invalidation affects the number of subsequent citations to the focal patent. We begin in column 1 by presenting the OLS estimate of the baseline specification relating external citations in a five year window after the court decision to the invalidity dummy and additional controls. There is no significant correlation between patent invalidation and future citations. This result is not causal, however. As we argued above, there are reasons why we should expect unobservable factors to affect both the invalidity decision of the Federal Circuit and subsequent citations. This intuition is confirmed by a Rivers-Vuong test that provides strong evidence against the exogeneity of invalidation. ${ }^{19}$

In order to address this endogeneity, we start with a conventional panel regression approach which controls for fixed patent effects, age dummies and year (group) dummies. The coefficient (standard error) on patent invalidity is $-0.068(0.022)$ which is very close to and not statistically different from the cross sectional OLS coefficient. This indicates that the main source of endogeneity is time-varying and cannot be dealt with by standard panel data methods.

In column 2 we move to an IV specification and instrument the Invalidated dummy with JIP. The estimate shows a statistically significant, positive effect between citations and

\footnotetext{
${ }^{19}$ Following Rivers and Vuong (1998), we regress Invalidated on JIP and the other controls in a linear probability model. We construct the residuals $(\hat{v})$ for this model and then regress subsequent citations on Invalidated, $\hat{v}$ and the other controls. The coefficient on $\hat{v}$ is negative and highly significant $(\mathrm{p}$-value $<0.01)$.
} 
invalidation by the Federal Circuit. The substantial difference between OLS and IV estimates highlights the importance of controlling for the endogeneity of invalidation, and indicates a strong negative correlation between Invalidated and the disturbance in the citation equation, $\varepsilon_{p}$ (inducing a large downward bias if we treat Federal Circuit invalidation as exogenous).

In column 3 we instrument Invalidated with the predicted probability of invalidation obtained from the probit regression (rather than JIP itself) from column 3 of Table 3 . This is more efficient as the endogenous regressor here is binary (Wooldridge, 2002) and, as expected, the F-statistic from the first stage regression increases from 17.4 to 94.8 when we replace $J I P$ with the predicted probability from the probit. The estimated coefficient implies that patent invalidation causes an increase in external citations of about 50 percent in the five years following the Federal Circuit decision. ${ }^{20}$ This increase in citations by other innovators does not necessarily imply that total follow-on innovation intensified, as it depends on what happens to the innovation by the owner of the invalidated patent. In column 4 we examine the relationship between invalidation and the number of total citations (including both external and self cites) received by the patent in the five years following the Federal Circuit decision. The estimated coefficient is very similar to the one obtained for external citations, which indicates that the increase in external citations is not compensated by a decline in self-citations. ${ }^{21}$

These instrumental variable regressions provide strong, causal evidence that the loss of patent rights increases subsequent citations to the patent. This evidence shows that, at least on average, patents block cumulative innovation. However, in the following sections we will show that this average effect is misleading because it hides the fact that the 'blocking effect' of patent rights is highly heterogenous. Moreover, we will reveal how the impact of patents varies with the characteristics of the patent, the patentee and the technology field.

\section{Robustness and Extensions}

We perform a variety of tests to confirm robustness of our main finding (details are provided in Appendix 3). In this section we briefly summarize the main robustness checks and describe

\footnotetext{
${ }^{20}$ Because the specification relates log of cites to the dummy variable Invalidated, we compute the marginal effect as $e^{0.41}-1=0.50$.

${ }^{21}$ In a companion research project, we are examining how patent invalidation affects self-citations as an indicator of how patent rights influence the direction of the firm's research trajectory. Our findings indicate that the effect of patent invalidation depends critically on whether the patent is central or peripheral to the patenting strategy of the firm.
} 
two extensions of the empirical analysis.

First, up to now we have treated an invalidation judgment as the final verdict. However, parties to the dispute have the right to appeal the decision of the Federal Circuit to the Supreme Court (which retains discretion over whether to hear the case). To deal with this issue we identified the patent invalidity cases appealed to the Supreme Court in our data set (there are only 12 cases). We drop these cases and re-estimate the model using instrumental variables. The point estimate of the coefficient on patent invalidation is very close to the baseline coefficient.

Second, the citations information obtained from the USPTO ends in 2010 so the latest years in the sample are subject to truncation. We run two robustness checks to assess whether truncation is an issue in our study. First, we restrict the sample to patent decisions that take place before 2003, where we have a complete 5-year time window of citations, and the results are similar to the estimates using the whole sample. Second, we adjust for truncation exploiting the citation lag distribution estimated in Hall, Jaffe and Trajtenberg (2001). They provide an estimate of the distribution of citations received over the life of patents across different technology classes that we use to inflate the citations received by patents for which we observe only a fraction of the five year window. The estimates from this procedure are also very similar to the baseline estimates.

Third, the baseline model incorporates fixed effects for six broad (one-digit) technology fields. To account for unobserved heterogeneity that might be related to narrower technology fields, we also estimate a specification that uses a more refined technology classification - 32 two-digit subcategories from the NBER. The point estimate of the coefficient on Invalidated is nearly double the baseline estimate but also less precise, and we cannot reject the null hypothesis that the two estimated coefficients are the same.

Fourth, to allow the age distribution of citations to vary across technology fields, we extend the specification by including a full set of interactions between the technology field and age dummies. The estimated coefficient on invalidation is nearly identical to the baseline coefficient. We also re-estimate the baseline model adding dummy variables for patents that received no cites before the Federal Circuit decision and for patents that receive no cites after the decision. The results are robust, and we also get similar estimates if we drop these patents from the sample entirely. 
Finally, there is a concern that some Federal Circuit decisions may involve rulings that limit the scope of patentable subject matter (e.g. software or business models) rather than simply assessing the validity of the focal patent. This type of invalidation could reduce subsequent citations for the entire technology field, leading us to underestimate the true blocking effect of patent rights (since we focus only on citations to the invalidated patent). To address this, we identified the most important Federal Circuit decisions that relate to patentable subject matter during our sample period. Dropping those decisions and re-estimating the model, we obtain coefficients that are nearly identical to the baseline estimates. ${ }^{22}$

We turn next to two extensions that are of independent interest. In the first extension we examine whether Federal Circuit invalidation has a smaller effect on older patents. In the extreme case where invalidation occurs after the patent has expired (there are such cases), the patent no longer has the power to block follow-on development so the invalidation decision should have no effect. More generally, for patents near statutory expiration we would expect to see less blocking effect, both because follow-on research is likely to have dissipated over time for old technologies and because the five year window after the invalidation decision will include years after expiration. We view these regressions as a kind of placebo test, providing additional support for the hypothesis that the invalidation effect is not being driven by other unobservable factors. Because of sample size, we cannot estimate the invalidation effect separately for each patent age. As an alternative, we examine how the estimated effect changes as we successively drop older patents. Column 1 of Table 5 shows that the effect of invalidation is slightly larger when we drop the 44 observations where patents are litigated after expiration (age 20). Columns 2 and 3 show that the effect continues to rise as we drop patents older than 18 and 15, respectively. Compared to our baseline estimate, the effect of invalidation is 28 percentage points larger for patents that are invalidated during their first 15 years of life. Finally, in column 4 we show that there is no effect of invalidation for patents whose Federal Circuit decision takes place more than 15 years after the filing date. ${ }^{23}$

\footnotetext{
${ }^{22}$ In Appendix 3 we also check whether the invalidation effect differs across quartiles of the patent value distribution as measured by the pre-decision external citations. We find no evidence of such differences. We also explore whether the invalidation effect is driven by citations by U.S. patents owned by foreign entities. We find that the invalidation effect is significant only for citations by domestic follow-on innovators. This result is interesting by itself because it is suggests that licensing frictions (removed by patent invalidation) must represent only a fraction of the total cost for foreign innovators to patent in U.S..

${ }^{23}$ We experimented with a variety of alternative specifications and obtain similar results. While there is clear
} 
In the second extension, we investigate the time path of the effect of invalidation on subsequent citations. Figure 2 plots IV estimates of the effect of invalidation in each of the ten years that follow invalidation, and the associated 90-percent confidence intervals. The results show that there is no statistically significant effect in the first two years after Federal Circuit invalidation. Moreover, the effects persist for seven years after the invalidation. ${ }^{24}$ This pattern suggests that the observed impact of invalidation is not simply due to a "media effect' from press coverage associated with the court decision, where we would expect a more immediate increase in citations and probably more rapid dissipation over time, which is not what we find. The estimated time path is more compatible with a story of entry of new innovators, previously blocked, developing technology building on the focal patent. In Section 8 we provide additional evidence which rules out media publicity, and we conduct a detailed analysis of where the blockage occurs, specifically, which technology fields and which types of patentees and downstream innovators.

\section{Heterogeneous Impacts of Patent Invalidation}

\section{Estimating the Marginal Treatment Effect}

To this point we have assumed that the effect of patent invalidation on future citations is constant across patents. However, as the theoretical discussion in Section 2 indicated, the impact of patents on later innovation depends on the risk of bargaining failure between upstream and follow-on innovators, and coordination failure among competing downstream developers. Thus we would expect the impact to vary with characteristics of the technology field, the transacting parties and market structure. In this section we extend the econometric model to explore this heterogeneity.

We begin by assuming that the effect of patent invalidation on future citations can be decomposed into a common component $\bar{\beta}$ and a random component $\psi_{p}$ : $\beta_{p}=\bar{\beta}+\psi_{p}$. We also

evidence that citations decline with age, the impact of invalidation does not systematically vary with the age of the invalidated patent. The only robust finding is that the invalidation effects drops to zero as patents approach expiration.

\footnotetext{
${ }^{24}$ These estimates are based on decisions in the 1982-2003 period, so that we have at least seven years of postdecision observations for every patent in the sample. If we include more recent years, or drop decisions after 2001, we still find that the statistically significant effects are concentrated in the third to sixth year following invalidation.
} 
assume that the probability of invalidity can be described as

$$
\text { Invalidated }\left(J I P_{p}, X_{p}\right)=\left\{\begin{array}{lll}
1 & \text { if } & P\left(J I P_{p}, X_{p}\right) \geq v_{p} \\
0 & \text { otherwise }
\end{array}\right.
$$

where $v_{p}$ is a characteristic of the patent case that is unobservable to the econometrician and which affects the invalidity decision. In general, we would expect this unobservable characteristic to be correlated (positively or negatively) with $\psi_{p}$. For example, if the patent is of higher quality (high $v_{p}$ ), invalidation would be less likely and the patent would be more likely to be cited after invalidation (high $\left.\psi_{p}\right)$. This example would imply that $E\left(\bar{\beta}+\psi_{p} \mid v_{p}\right)$ is increasing in $v_{p}$.

Because $v_{p}$ is not observed, we cannot condition on it. Nonetheless, for a patent case decided by a panel of judges that is just indifferent between invalidating and not invalidating, it must be that $P\left(J I P_{p}, X_{p}\right)=v_{p}$. Exploiting this equality, we can identify the marginal treatment effect as $E\left(\bar{\beta}+\psi_{p} \mid P\left(J I P_{p}, X_{p}\right)\right)$, which corresponds to the (heterogenous) effect of invalidation on future citations for patents that are invalidated because of the instrument. Carneiro, Heckman, and Vytlacil (2010) provide a formal treatment, where they show that

$$
E\left(\bar{\beta}+\psi_{p} \mid P=v_{p}\right)=\left.\frac{\partial E\left(\log \left(\text { PostCites }_{p}+1\right) \mid P\right)}{\partial P}\right|_{P=v_{p}}
$$

and establish identification of the marginal treatment effect (MTE).

In Figure 3 we present estimates of the MTE. The horizontal axis depicts the estimated probability that the patent is invalidated. The vertical axis shows the effect of invalidation on post decision citations for different values of this probability. The support for the estimated probability goes from the $10^{\text {th }}$ to the $90^{t h}$ percentile. The estimated marginal treatment effect is increasing in the probability $P$. Patents with low values of $P$ are those that, given observables, are unlikely to be invalidated. The small and insignificant values for the MTE in this range show that, if an increase in judge propensity to invalidate leads to invalidation of the patent, the effect of invalidation on citations would be negligible. Conversely, patents with high $P$ are patents with high risk of invalidation based on observable characteristics. For these patents the MTE is positive, indicating that citations increase after invalidation. ${ }^{25}$

\footnotetext{
${ }^{25}$ These findings are robust to using alternative estimation methods to compute the MTE, including a nonparametric approach and the semiparametric approach (with a third order polynomial) proposed by Carneiro, Heckman, and Vytlacil (2010).
} 
The estimated MTE shows substantial heterogeneity in the effect of patent protection on cumulative innovation. The finding of an increasing MTE also helps identify mechanisms that drive the increase in citations that we observe after Federal Circuit invalidation. This is because the MTE estimates the effect of invalidation for patent cases in which judges are indifferent between a validity and an invalidity ruling. Thus, an increasing MTE indicates that the effect of invalidation on citations is greater for patents which, despite having observable features that make invalidation likely (high $P\left(J I P_{p}, X_{p}\right)$ ), are characterized by unobservable factors that make invalidation less likely (large $v_{p}$ ). An example would be characteristics that affect the strength of the patent (legal enforceability) and thus make invalidation less likely, and which are observable to the patentee but unobservable to the licensees (and well as the econometrician). This asymmetric information can lead to bargaining failure in licensing negotiations. In such cases, Federal Circuit invalidation can facilitate access to the technology that was blocked by the bargaining failure.

\section{Explaining the Heterogeneity}

We showed that the effect of patent invalidation on subsequent citations is concentrated among a small subset of patents. We turn now to unbundling the heterogenous impact of patent rights by relating it to observable characteristics of the technology field and contracting environment.

Previous empirical studies emphasize two features of the innovation environment that affect bargaining between upstream and downstream firms, and thus the incentives to invest in follow-on innovation. The first is the concentration of patent ownership in the technology field. For example, Ziedonis (2004) argues that when patent ownership is not concentrated (i.e. fragmented), downstream innovators need to engage in multiple negotiations, which exacerbates the risks of bargaining failure and ex post hold-up. However, from a theoretical perspective the relationship between fragmentation of patent ownership and the blocking effect of patent rights is ambiguous. Existing models of contracting over patents indicate that the value obtained from accessing an additional patent in a fragmented environment depends critically on the degree to which patents are complements or substitutes (Lerner and Tirole, 2004; Galasso and Schankerman, 2010).

The second feature is the 'complexity' of the technology field. In complex fields, new products embody numerous patentable elements, as contrasted with 'discrete' technology areas 
where products build only on few patents. When products typically incorporate many patented inputs, and they are held by different owners, licensees need to engage in multiple negotiations and the risk of bargaining failure is higher. Thus we expect the impact of patent rights on cumulative innovation to be more pronounced in complex technology fields.

To test these hypotheses, we construct two variables. The first variable, Conc4, is a concentration measure equal to the patenting share of the four largest assignees in the technology subcategory of the litigated patent during the five years preceding the Federal Circuit decision (the mean and standard deviation of Conc4 are 0.067 and 0.053 , respectively). The second variable, Complex, is a dummy variable for patents in complex technology fields. Following Levin et. al. (1987) and Cohen, Nelson and Walsh (2000), we classify electrical and electronics (NBER category 4), computers and communication (NBER category 2) and medical instruments and biotechnology (NBER subcategories 32 and 33) as complex technology fields.

In columns 1 and 2 of Table 6 we show, in two split sample regressions, that the effect of patent invalidation is small and statistically insignificant among patents in concentrated technology areas (Conc4 $\geq$ median), whereas it is large and statistically significant among patents in fragmented technology fields (Conc4 < median). Similarly, columns 3 and 4 show that the effect of invalidation is more than twice as large in complex technology areas as compared to the non-complex technology fields. Column 5 provides estimates using the full sample and interacting Conc4 and Complex with the Invalidated dummy. These confirm the findings from the split sample regressions. Evaluated at their respective sample means of Conc4, our point estimate (standard error) for complex technology fields is 1.149 (0.29); for non-complex fields it is not statistically different from zero, at 0.167 (0.23). For complex fields the estimate implies that patent invalidation raises subsequent citations by 216 percent. We also confirm that concentration substantially mitigates the effect of patent invalidation on future citations: a one standard deviation increase in Conc4 reduces the effect of invalidation by 0.37 , which is 32 percent of the estimated impact for complex fields. ${ }^{26}$

\footnotetext{
${ }^{26}$ Column 5 also controls for the direct effect of Conc4 and includes additive technology dummies that absorb the direct effect of Complex. These results are unchanged if we reclassify biotechnology patents (subcategory 33) as a non-complex field, or if we replace the continuous concentration measure with a dummy variable for fields with Conc4 above the 50th or 75 th percentile. We also use our parameter estimates (column 5, Table 6) to examine how variation over time within fields affects the impact of invalidation. To do this, we construct the Conc 4 measure for each technology subcategory in the years 1982-2002 and compute a weighted average for each of the six broad technology fields, with weights equal to the fraction of patenting in the area. We find no evidence of significant changes in the impact of patent invalidation during our sample period.
} 
We can use the parameter estimates from column 5 to compute the implied effect of patent invalidation on citations for each of the technology fields, based on the observed values of Conc4 and Complex for each field. The results, presented in column 1 of Table 7, are striking. There is essentially no effect of patent rights on cumulative innovation in any of the three non-complex technology areas - pharmaceuticals, chemicals and mechanical. By contrast, the effect is large and statistically significant in each of the complex fields - the coefficients imply that invalidation raises citations by 320 percent in medical instruments/biotechnology, 203 percent in electronics and 178 percent in computers. For comparison, column 2 reports estimates of split-sample regressions for each technology field. Though the smaller sample sizes reduce precision, the regressions confirm strong impacts in medical instruments/biotechnology and computers, but no statistically significant effect in electronics.

However, one concern with our finding that patent rights do not block follow-on innovation in drugs is that the litigation in that sector may be brought primarily by generic drug firms whose business model is to produce off-patent drugs rather than to innovate by building on previous drugs. In this case, finding that patent invalidation has no effect would simply be due to an absence of interest by follow-on innovators, and could not be interpreted as evidence that licensing negotiations are effective. In order to address this concern, we conducted a full text search of the invalidity decisions involving pharmaceutical patents in our sample to identify cases related to 'Abbreviated New Drug Application' (ANDA) by generic firms. ${ }^{27}$ We re-estimate the model allowing the invalidity coefficient to be different for ANDA and other drug cases, but we find no statistically significant difference.

Overall, these findings indicate that the fragmentation of patent ownership and complexity of technology fields are key empirical determinants of the relationship between patent rights and cumulative innovation. Of course, other factors can also affect the impact of patent rights on subsequent innovation. One is product market competition. Aghion, Howitt and Prantl (2013) provide evidence that strong patent protection stimulates innovation only when product market competition is fierce. A second factor is the degree to which 'tacit cooperation' can

\footnotetext{
${ }^{27}$ To do this, we identified references to at least one of the following terms: paragraph IV, Hatch-Waxman, Abbreviated New Drug Application, and ANDA. We find that about 25 percent (45 cases out of 167) of the drug patent decisions in our sample mentioned at least one of these terms, and we generated a dummy variable to capture such ANDA litigation. This is a conservative measure (upper bound) because these terms may also appear outside ANDA cases.
} 
be used by firms to mitigate potential bargaining failures and litigation that might otherwise arise from dispersed ownership of patent rights (Lanjouw and Schankerman, 2004). Understanding where and how these differences operate is a valuable direction for future theoretical and empirical research.

Our findings are relevant to the current policy debates on patent reform. The recent literature studies specific innovations in biotechnology and medical instruments and finds blocking effects (Murray and Stern, 2007; Murray et. al. 2008 and Williams, 2013). Our estimates confirm the presence of blocking in these fields, using a much broader set of innovations and an entirely different identification strategy. But our results also show that the effect is very different in other fields, and thus remedial policies to mitigate blocking need to target specific technology areas in order to preserve innovation incentives. At the same time, changes in the contracting environment in which technology licensing takes place would reshape the relationship between patent rights and cumulative innovation.

\section{$6 \quad$ Intensive versus Extensive Margins}

In the previous section we showed that the blocking effect of patents on later innovation depends on how concentrated patent rights are - i.e., on the 'industrial organization' of innovation. However, the influence can also run in the other direction. Patent rights can shape the industrial structure of innovation by impeding the entry of new innovators or the expansion of existing firms, and this potential blocking effect may be stronger for certain kinds of patentees or downstream innovators. In this section we examine this issue and show that the blocking effect of patents depends critically on the size of the patentee and the downstream innovators.

We measure the size of the citing innovators by constructing the portfolio size for each assignee citing the patents involved in Federal Circuit litigation. The portfolio is defined as the number of patents granted to an assignee in the five years before the Federal Circuit decision. The mean portfolio size of citing firms is 359 patents but the distribution is very skewed - the median firm has only 5 patents, and the 75th percentile has 102 patents. We assign firms to one of three size categories: 'small' if its portfolio is below five, 'medium' if the portfolio is between 6 and 101 patents, and 'large' if it greater than 102 patents. We study how patent invalidation affects citations by subsequent innovators in each size group. In each regression we also allow for the effect of invalidation to be different when the focal patent is held by a 
large patentee, defined as one with a patent portfolio of more than 102 patents. $^{28}$

In addition, for each size group, we investigate whether the blocking effect of patent rights works through reducing the number of later innovators building on the focal patent or on the intensity of their downstream innovation. This question is of interest because the effect of patent rights on the industrial structure of innovation differs in the two cases. To examine this issue, we decompose the total number of later citations into intensive and extensive margins. We measure the extensive margin by the number of distinct patent owners (assignees) citing the focal (litigated) patent in the five-year following the Federal Circuit decision. We measure the intensive margin by the number of citations per assignee to the focal patent in the same time window.

Table 8 presents the IV estimates of the patent invalidation effect on citations by different size groups. Focusing first on the total number of external citations (columns 1-3), the estimates reveal that the blocking effect of invalidation is concentrated exclusively on citations that patents of large firms receive from small innovators. The magnitude of the implied blocking effect is very large: invalidation of a large firm patent increases small firm citations by about 520 percent. This is consistent with our earlier estimate of 50 percent for the average blocking effect in the overall sample, because roughly 50 percent of the citing entities are small firms in our data and about 20 percent of the patentees are large firms (i.e., $520 \times 0.5 \times 0.2=52$ percent). The coefficients for the other size groups are much smaller in magnitude and statistically insignificant.

In columns 4-6, we study how patent invalidation affects the extensive margin. The dependent variable in these regressions is the logarithm of one plus the number of distinct assignees citing the litigated patent in the five years following the Federal Circuit decision. Here too we find that the blocking effect of patents is concentrated exclusively among citations by small firms to large firm patents. The estimated coefficient of 1.347 implies a 285 percent increase in the number of distinct small assignees citing the patent when a patent of a large firm is invalidated by the Federal Circuit. The effects for the other size groups again are small

\footnotetext{
${ }^{28}$ In classifying firms, we do not correct for changes in patent ownership because more than 65 percent of our patents do not belong to the re-assignment dataset constructed by Serrano (2010). To address this issue, we manually match the assignee name of the litigated patent at the grant date with the names of the litigated parties. For 134 patent cases we notice a discrepancy between the USPTO name and the names of the litigants. Replacing the patent portfolios of original patent assignee with the portfolios of the litigating party we obtain results that are essentially identical to those reported below in Table 8 .
} 
and statistically insignificant. Finally, columns 7-9 examine the blocking effect at the intensive margin, the number of citations per distinct patent owner. The only coefficient (marginally) significant is again the one related to large patentees and small citing assignees. The effect of invalidation is about 62 percent, but statistically significant only at the 10 percent level. Overall, we cannot reject the hypothesis that the extensive margin effect for small citing firms is equal to the total effect and that the intensive margin effect is zero. In Appendix 4 we present a series of additional regressions varying the threshold for defining small and large firms. These experiments show that the pattern emerging in Table 8 is extremely robust.

These findings show that patent rights block later innovation in very specific ways, not uniformly. The fact that we see no statistically significant blocking effect for most size categories suggests that bargaining failure among upstream and downstream innovators is not widespread. However, the results show that bargaining breakdown occurs when it involves large patentees and small downstream innovators. This finding is consistent with Lanjouw and Schankerman (2004), who show that small firms are less able to resolve disputes 'cooperatively' without resorting to the courts. Small firms do not have patent portfolios that can be used as counterthreats to resolve disputes or to strike cross-licensing agreements to preserve freedom to operate in their innovation activities (Galasso, 2012).

Finally, we emphasize that our findings are not driven by the recent surge in litigation activity by non-practicing entities (NPE, aka "trolls") blocking follow-on research of small firms. This is because very few NPE patent cases reach the Federal Circuit court. The large anecdotal evidence on trolls shows that the most common business strategy for NPE's is to threaten litigation and demand a settlement fee that alleged infringers prefer to pay rather than face the cost and risk of litigation. To check this for our sample, we obtained a list of 50 leading patent trolls from Fisher and Henkel (2012) and manually matched their names against the litigants in our sample. We find that only 12 patent cases in our sample involve a troll. When we drop these observations and re-estimate the model, we obtain estimates that are essentially identical to those obtained in our full sample regressions.

\section{Using Non-Patent Measures of Follow-on Innovation}

To this point we have used the number of subsequent citations as our measure of followon innovation, which is the conventional approach. We are aware of very few exceptions. 
Williams (2013) studies the impact of patent rights on human genome research using both citations in later scientific publications and direct measures of product development. Moser and Rhode (2011) study the impact of the 1930 Plant Patent Act on plant innovation by tracking registration of new rose varieties with the American Rose Society. Using product level information is clearly desirable, but citations are the only practical measure for studies that cover a wide range of technology fields, such as ours. From an economic perspective, patent citations play two distinct roles: they indicate when a new invention builds on prior patents (and thus may need to license the upstream patent), and they identify prior art that circumscribes the property rights that can be claimed in the new patent. Citations can either under- or overestimate the extent of follow-on innovation. They will underestimate it where inventors develop improvements that are not patented (or patentable), but overestimate it when the inventor did not actually built on the prior patent. In any event, there are serious hurdles to using product-level data to measure innovation across a wide range of technology fields. First, there are no comprehensive data sets of products in different industries, and second, there is no way to identify whether a product specifically builds on a previous patent.

Fortunately, however, we are able to construct non-patent measures of follow-on innovation for two of our technology fields - pharmaceuticals and medical instruments - thanks to government regulation that requires registration of new product developments in these areas. These cover both a 'discrete' technology field (drugs) in which we found no blocking effect using the citations measure, and a 'complex' one (medical instruments) where we found a strong blocking effect. In this section we show below that these findings also hold up when we use product-based measures.

\section{Medical Instruments}

The Food and Drug Administration (FDA) has primary authority to regulate medical devices sold in U.S. These products are subject to a regulatory process that requires detailed product information and evidence of safety from clinical trials. The FDA releases data on approvals requested for medical instruments. To use these FDA approval requests as a measure of follow-on innovation, we need to link them to the medical instrument patents in our sample. To do this, we use two alternative approaches. First, we search the text of the abstract in each of our litigated patents to identify a set of keywords related to the patented technology. We then search for all FDA approval requests to identify those that contain these keywords. 
In the second approach, we assign each our litigated patents to a set of product codes from among the roughly 6,000 product codes in which the FDA classifies medical devices. We then use all of the FDA approval requests listed in the corresponding product codes as our measure of follow-on innovation. Appendix 5 provides details of the data construction and discussion of the merits and limitations of each approach.

We re-estimate the baseline model using each of these measures of follow-on innovation. Panel A in Table 9 summarizes the IV estimates of the patent invalidation effect for the medical instrument patents. Column 1 presents the estimate using citations as the dependent variable, which is statistically significant ( $\mathrm{p}$-value $=0.053$ ) and very similar to the one reported in column 2 of Table 7. The slight difference in magnitude and smaller sample size are due to our focus on medical instrument patents, where we exclude biotechnology patents. Column 2 shows the estimated effect where we measure follow-on innovation with the number of FDA approval requests for which the product name contains at least one of the keywords from the litigated patents. Again we find a positive and statistically significant ( $\mathrm{p}$-value $=0.06)$ invalidation effect. The point estimate is smaller than (but not statistically different from) the one based on citations. In column 3 we measure follow-on innovation by the number of applications for the product codes in which the patent is classified. Here too the point estimate is broadly in line with (and not statistically from) the one estimated with citations. In Appendix 5 we show that these results are generally robust to how we define the keywords and product codes used to map between the FDA-registered medical devices and our litigated patents.

Overall, this analysis confirms our conclusion that patent invalidation has a significant impact on cumulative innovation in the complex technology field of medical instruments.

\section{Pharmaceuticals}

We construct a measure of follow-on innovation by identifying the subsequent clinical drug trials that are related to the active ingredient of the litigated drug patent. The use of clinical trials as a measure of innovation is natural in the health sector and has been recently exploited in economic research (e.g., Finkelstein (2004) for vaccine research; Budish, Roin and Williams (2014) for cancer drug research). Our data source for clinical trials is the web-site ClinicalTrials.gov, which is a registry and results database of publicly and privately supported clinical studies of human participants. Because the site only reports clinical trials from 2000 onwards, we can construct this alternative measure only for patents litigated in the Federal 
Circuit after 1997.

We use two approaches to match Federal Circuit drug patents with clinical trials. For 94 patent cases, we were able to identify the trade name of the drug protected by the patent and the clinical trials related to the active ingredient of the specific drug. For the remaining cases, we collected a set of keywords describing the new drug compound after careful reading of the patent title and abstract. We match the drug patents to subsequent clinical trials based on the appearance of these keywords. Appendix 5 provides additional details on the data construction.

Panel B in Table 9 presents the estimates of the invalidation effect for our drug patents using these measures of follow-on innovation. To facilitate comparison, column 1 reports the results obtained in our split sample regression with citations as the dependent variable. In column 2 we present the estimate using the number of trials as dependent variable, for the subset of sample patents that we were able to match to a commercialized drug. The point estimate is positive and very close to one obtained using the citations measure, but again it is statistically insignificant, confirming that patent rights do not block cumulative innovation in drugs. Column 3 shows that results are similar in the extended sample constructed with keyword matching. In Appendix 5 we discuss robustness of these results. Across a variety of sub-samples and specifications, we find no evidence of a statistically significant effect of invalidation in pharmaceuticals.

Overall, this analysis with product-based measures of innovation confirms our earlier conclusions from regressions based on patent citation data. The analysis also suggests that non-patent measures are not necessarily superior to patent measures. Despite their limitations, patent citations have the advantage of directly linking each litigated patent with follow on technologies exploiting information revealed by later patenting innovators (or patent examiners). The non-patent measures require more subjective choices by the econometrician in making these links. While we explored the robustness of our measures (e.g., collecting a variety of keywords for each patent and linking it to products using different subsets of these keywords discussed in Appendix 5), there is no reason to expect the measurement error in this process to be lower than the one from citations. Moreover, using patent citations to measure follow-on innovation has the advantage of ensuring that we focus on technologies that pass the novelty and non-obviousness requirements for patentability. Any non-patent measure may also include 
subsequent products that do not pass this standard. Despite the fact that there is no single dominant measure, the existence of multiple indicators can potentially provide a more informative composite index of the underlying phenomenon of interest (as shown by Lanjouw and Schankerman (2004) in the context of measuring patent quality). This is a potentially fruitful direction for future research.

\section{Testing Alternative Interpretations}

On average, patent invalidation causes a substantial increase in subsequent citations to the focal patent. This result suggests that some licensing deals are not taking place in the presence of patent protection. There are two main reasons why this might occur. First, it might be privately optimal for a patent owner to restrict access if licensing reduces joint profits (e.g., because it intensifies downstream competition). Second, information asymmetry and uncoordinated, multilateral bargaining can lead to licensing failures even when such agreements would increase joint profits (and consumer surplus). It is important to distinguish between these explanations because they differ in terms of their implications for welfare and policy.

Our empirical findings suggest that bargaining failure is a significant part of the explanation. Support for this claim is found in the estimated heterogeneous marginal treatment effects. The impact of patent invalidation is concentrated on a small subset of patents, and these have unobservable characteristics that are associated with a lower likelihood of being invalidated (i.e., stronger patents). This suggests the presence of asymmetric information that would be expected to induce bargaining failure in licensing. Moreover, our results help pin down where the bargaining failure occurs. The effect is concentrated in fields characterized by two features: complex technology and high fragmentation of patent ownership. We find no evidence of blocking in non-complex fields such as chemicals, pharmaceuticals or mechanical technologies. This reinforces the market failure interpretation, since earlier studies identify fragmentation and complexity as key determinants of licensing breakdown (Cohen, Nelson and Walsh, 2000; and Ziedonis, 2004). ${ }^{29}$

\footnotetext{
${ }^{29}$ Our conclusion that patent rights only block in specific environments may be overly optimistic. An alternative explanation for why we do not find blockage in other settings is that patentees are simply unable to enforce their rights effectively. In this case, the $R \& D$ incentives for upstream innovators would be diluted, making welfare implications of patent rights more ambiguous. We do not think that this interpretation is plausible for two reasons. First, our sample covers high value patents whose owners have expended substantial resources to reach the Federal Circuit court, and this does not fit well with an assumption that their patent rights are
} 
We interpret our finding that patent invalidation increases later citations by other firms as evidence that the focal patent was blocking innovation by those firms. However, there are three possible reasons for believing that this interpretation of our results may lead us to overestimate the degree to which patent rights effectively block follow-on innovation. Rather than blocking, the post-invalidation increase in citations could reflect: 1) substitution by users from other patents to the focal patent, 2) media publicity, or 3) strategic citation by downstream innovators. In the remainder of this section we address each of these arguments.

\section{Substitution among Patents}

The post-invalidation increase in citations we estimate could be generated by substitution by downstream innovators away from other patented technologies toward the invalidated patent which is now cheaper to use. However, there are two reasons why we think this substitution effect is unlikely to account for the entire increase in citations we estimated. First, our sample comprises highly valuable patents for which litigants spent substantial resources in district court and appellate litigation. It is implausible that such expensive litigation takes place if parties can easily substitute the patented technology with an alternative one. Second, the invalidation effect crucially depends on the characteristics of patentees and citers. We see no statistically significant effect for most size categories, it being concentrated entirely between large patentees and small downstream innovators. This finding is hard to explain with simple technology substitution, since it is not obvious why an invalidated patent should be used as a substitute technology by small innovators only if it is held by a large patentee.

Nonetheless, we explore this issue more constructively by examining whether patent invalidation also leads to a decline in the number of citations to patents that are putative substitutes for the Federal Circuit patent. To this end, we construct a sample of 'related' patents for each litigated patent in our sample. To do this, we use the Google Prior Art software, which is a text based matching algorithm that identifies and ranks related patents. Appendix 6 provides details of the data construction.

We run a series of IV regressions that relate the post-decision citations to the related (substitute) patents, controlling for the endogeneity of invalidation with the same approach as our baseline regression. Table 10 reports the results. In column 1, the sample is limited to the 
substitute patents identified as the highest ranked Google match for each Federal Circuit patent (when at least one was identified). Columns 2 and 3 focus, respectively, on the top two and three highest ranked matches for the Federal Circuit patents. In each of these IV regressions, the estimated coefficient on the patent invalidation dummy is negative, suggesting that there is some role for the substitution interpretation. However, the point estimates are statistically insignificant in two of the samples, and only marginally significant, at the 10 percent level, in the sample using two related patents. Even in the latter case, the estimated coefficient is too small to account for the impact of invalidation on citations to the focal patent that we found. The point estimate implies that invalidation of the focal patent leads to a 15.5 percent reduction in citations to related (substitute) patents, which can explain only one-fifth of the estimated effect of Federal Circuit invalidation on the focal patent. ${ }^{30}$ This finding does not necessarily imply that the level of technical substitution is small. It is possible that a decline in citations due to technical substitutability could be compensated by an 'innovation burst' or market expansion effect generated by the court decision which increases citations for both the invalidated patent and related patents. Nonetheless, our objective is to estimate the total effect of invalidation on related patents, not to isolate the technical substitution from the market expansion effect.

\section{Media Publicity from Court Decision}

The increase in citation after patent invalidation could be driven, at least in part, by publicity associated with the Federal Circuit decision. Our instrumental variable estimation partially addresses this concern, since press coverage is unlikely to be disproportionately greater for patents that have been (randomly) allocated to judges with high propensity to invalidate. Nonetheless, to provide further evidence, we collected data on news coverage for the cases in our sample. Our main source is the Dow Jones Factiva dataset, which collects press releases in the major international news and business publications. We classify an article as relevant press coverage if it contains at least one of the names of the litigating parties as well as all the following words: 'patent', 'litigation', 'court' and 'appeal'. We construct a measure, MediaMentions, defined as the number of articles referring to the case in a one-year window

\footnotetext{
${ }^{30}$ Related patents receive only 48 percent as many citations as Federal Circuit patents (1.2 and 2.5 citations per year, respectively). So a 15.5 percent decline in citations to each of two related patents translates to a 15 percent ( 2 patents $\times 0.155 \times 0.48$ ) increase in citations to Federal Circuit patents, which is about $1 / 5$ of the 70 percent increase estimated in the sample of matched litigated patents.
} 
centered around the date of the Federal Circuit decision (i.e., six months before and after the decision date). When we add MediaMentions to our baseline specification, and estimate using our instrumental variable approach, we find that this new variable has no statistically significant effect on citations, and more importantly, that our estimated coefficient on Invalidated is very close to the baseline estimate (column 4 in Table 10).

\section{Strategic Citation}

Finally, the increase in citations caused by patent invalidation could reflect the propensity of small patentees to 'strategically withhold citations' to patents of large firms in order to stay below their radar screen, rather than a real blocking impact on the underlying innovation by small firms. There are several reasons why we think that this strategic behavior is unlikely to play a big role in our setting. First, previous studies show that large firms are more likely to withhold citations strategically (Lampe, 2012), whereas we find that the effect of invalidation is driven by a post-decision increase in citations by small firms. Second, our measure includes citations both by the patent applicant and those added by the USPTO examiner. Thus an increase in citations after invalidation would imply, not only strategic behavior by the applicants, but also errors by examiners in overlooking relevant prior art. Our estimated impact - a 520 percent increase in citations from small firms - would imply an unreasonably large error rate by patent examiners, especially given that our sample contains well known patents. Finally, the strategic citation interpretation is hard to reconcile with a lagged effect of patent invalidation on later citations, which we documented in Section 4.

In view of the preceding discussion, we interpret our findings as evidence in support of the conclusion that patent rights block follow-on innovation in a few specific technology fields. However, we emphasize that our findings do not imply that removal of patent rights in these areas would necessarily be beneficial. This is because invalidation of one patent in a regime with patent rights is very different from a regime without patent rights. First, in the presence of patent rights, research is conducted under the expectation of obtaining rents in the form of product market monopoly profits and licensing royalties from follow-on innovators. These rents would be expected to (largely) disappear in a regime without patents and this would reduce, perhaps sharply, incentives to conduct such R\&D. Moreover, theoretical models of cumulative innovation show that such policies have ambiguous effects on overall innovation incentives. In models with two generations, weaker patent protection shifts rents toward downstream firms, 
increasing their incentives but reducing incentives for first generation research. The role of patent rights is even more ambiguous in a fully dynamic setting, where each innovation is both upstream and downstream at different stages of its life (Green and Scotchmer, 1995; Hopenhayn, Llobet and Mitchell, 2006). Second, economic research has documented that patents play an important signalling role in capital markets, and in particular, enable small firms to attract venture capital investors more effectively (e.g. Conti, Thursby and Thursby, 2013). Third, we would expect the direction of technical change to be different in a regime without patents. Innovators will have greater incentives to invest in research that can be more easily protected through trade secrets and for which reverse engineering and copying is more difficult. Moser (2005) provides some supporting evidence for this idea using data from nineteenth century World Fairs. All these issues would need to be part of a broader welfare assessment of patent rights, but this is beyond the scope of the paper.

\section{Concluding Remarks}

In this paper we estimate the causal effect of patent rights on cumulative innovation, using patent invalidation decisions of the U.S. Federal Circuit Court of Appeals. The identification strategy exploits variation in the propensity of judges to invalidate and the fact that the threejudge panels are generated by a random computer algorithm. There are three key empirical findings in the paper. First, invalidation leads to a 50 percent increase in subsequent citations to the focal patent, on average. Second, the impact of patent invalidation is highly heterogeneous, with large variation across patents and technology fields in ways that are consistent with the blocking effect of patents arising from bargaining failure between upstream and downstream innovators. Third, we find that this effect is concentrated in patents owned by large firms that appear to block small innovators.

While a welfare assessment of patent rights is well beyond the scope of this paper, our findings provide good reason to believe that a wholesale scaling back of patent rights may not be the appropriate policy. Patent rights block cumulative innovation only in very specific environments, and this suggests that government policies to address this problem should be targeted. It is preferable to design policies and institutions that facilitate more efficient licensing (such as the biomedical institutions studied by Furman and Stern, 2011), which is the key to removing the blocking effect of patents and promoting cumulative innovation. 


\section{References}

[1] Acemoglu, Daron (2012), "Diversity and Technological Progress," in Josh Lerner and Scott Stern, eds., The Rate and Direction of Inventive Activity Revisited (Chicago: University of Chicago Press): 319-356

[2] Acemoglu, Daron and Ufuk Akcigit (2012), "Intellectual Property Rights Policy, Competition and Innovation," Journal of the European Economic Association, 10: 1-42

[3] Aghion, Philippe and Peter Howitt (1992), "A Model of Growth through Creative Destruction," Econometrica, 60: 323-351

[4] Aghion,Philippe, Peter Howitt and Susanne Prantl (2013), "Patent Rights, Product Market Reforms, and Innovation," NBER Working Paper 18854

[5] Angrist, Joshua, Guido Imbens and Alan Krueger (1999), "Jackknife instrumental variables estimation," Journal of Applied Econometrics, 14: 57-67

[6] Azoulay, Pierre, Joshua Graff Zivin and Jialan Wang (2012), "Superstar Extinction," Quarterly Journal of Economics, 125: 549-589

[7] Bessen, James and Eric Maskin (2009) "Sequential innovation, patents, and imitation," RAND Journal of Economics, 40: 611-635

[8] Bloom, Nick, Mark Schankerman, and John Van Reenen (2013), "Identifying Technology Spillovers and Product Market Rivalry," Econometrica, 81: 1347-1393

[9] Bolton, Patrick and Joseph Farrell (1990), "Decentralization, duplication and delay," Journal of Political Economy 98: 803-826

[10] Budish, Eric, Benjamin Roin and Heidi Williams (2014), "Do Fixed Patent Terms Distort Innovation? Evidence from Cancer Clinical Trials," NBER working paper 19430

[11] Carneiro, Pedro, James Heckman and Edward Vytlacil (2010) "Evaluating Marginal Policy Changes and the Average Effect of Treatment for Individuals at the Margin," Econometrica, 78: 377-394

[12] Cohen, Wesley, Richard Nelson and John Walsh (2000) "Protecting Their Intellectual Assets: Appropriability Conditions and Why U.S. Manufacturing Firms Patent (or Not)," NBER Working Paper 7552

[13] Conti Annamaria, Jerry Thursby and Marie Thursby (2013), "Patents as signals for startup financing," Journal of Industrial Economics, 22: 592-622

[14] Crawford, Vincent, and Haller, Hans (1990) "Learning How to Cooperate," Econometrica 58: $571-595$

[15] Cremer, Jacques and Richard McLean (1985) "Optimal Selling Strategies under Uncertainty for a Discriminating Monopolist When Demands Are Interdependent," Econometrica 53: $345-361$

[16] Dahl, Gordon, Andreas Kostol and Magne Mogstad (2013), "Family Welfare Cultures", NBER working paper 1937 
[17] Di Tella, Rafael and Ernesto Schargrodsky (2013), "Criminal Recidivism after Prison and Electronic Monitoring," Journal of Political Economy, 121: 28-73

[18] Dobbie Will and Jae Song (2013), "Debt Relief and Debtor Outcomes: Measuring the Effects of Consumer Bankruptcy Protection," working paper

[19] Doyle, Joseph (2007), "Child Protection and Child Outcomes: Measuring the Effects of Forster Care," American Economic Review, 97: 1583-1610

[20] Doyle, Joseph (2008), "Child Protection and Adult Crime: Using Investigator Assignment to Estimate Causal Effects of Foster Care," Journal of Political Economy, 116: 746-770

[21] Feddersen, Timothy and Wolfgang Pesendorfer (1996), "The Swing Voter Curse," American Economic Review, 86: 408-424

[22] Federal Trade Commission (2011), The Evolving IP Marketplace: Aligning Patent Notice and Remedies with Competition, (Washington D.C.: Government Printing Office)

[23] Finkelstein, Amy (2004), "Static and Dynamic Effects of Health Policy: Evidence from the Vaccine Industry," Quarterly Journal of Economics 119: 527-564

[24] Fisher Timo and Joachim Henkel (2012), "Patent trolls on markets for technology - An empirical analysis of NPEs' patent acquisitions," Research Policy 41: 1519-1533

[25] Furman, Jeffrey and Scott Stern (2011), "Climbing atop the Shoulders of Giants: The Impact of Institutions on Cumulative Research," American Economic Review, 101: 19331963

[26] Galasso, Alberto (2012), "Broad Cross-License Negotiations," Journal of Economics and Management Strategy, 21: 873-911

[27] Galasso, Alberto and Mark Schankerman (2010), "Patent Thickets, Courts and the Market for Innovation", RAND Journal of Economics, 41: 472-503

[28] Galasso, Alberto, Mark Schankerman and Carlos Serrano (2013), "Trading and Enforcing Patent Rights," RAND Journal of Economics, 44: 275-312

[29] Green, Jerry and Suzanne Scotchmer (1995), "On the Division of Profit in Sequential Innovation," RAND Journal of Economics, 26: 20-33

[30] Griliches, Zvi (1992), "The Search for R\&D Spillovers," Scandinavian Journal of Economics, 94: 29-47

[31] Grossman, Gene and Elhanan Helpman (1991), Innovation and Growth in the Global Economy (Cambridge: MIT Press)

[32] Hall, Bronwyn, Adam Jaffe and Manuel Tratjenberg (2001), "The NBER Patent Citation Data File: Lessons, Insights and Methodological Tools," NBER Working Paper 8498

[33] Heller, Mark and Rebecca Eisenberg (1998), "Can Patents Deter Innovation? The Anticommons in Biomedical Research," Science, 280: 698-701 
[34] Henry Matthew and John Turner (2006), "The Court of Appeals for the Federal Circuit's Impact on Patent Litigation," Journal of Legal Studies, 35: 85-117

[35] Hopenhayn, Hugo, Gerard Llobet and Matthew Mitchell (2006), "Rewarding Sequential Innovators: Prizes, Patents and Buyouts," Journal of Political Economy, 114: 1041-1068

[36] Kitch, Edmund (1977), "The Nature and Function of the Patent System," Journal of Law and Economics, 20: 265-290

[37] Kling, Jeffrey (2006), "Incarceration Length, Employment and Earnings," American Economic Review, 96: 863-876

[38] Koo, Bonwoo and Brian Wright (2010), "Dynamic Effect of Patent Policy on Sequential Innovation," Journal of Economics and Management Strategy 19, 489-512

[39] Lampe, Ryan (2012), "Strategic Citation," Review of Economics and Statistics 94: 320-333

[40] Lanjouw, Jean and Mark Schankerman (2001), "Characteristics of Patent Litigation: A Window on Competition," RAND Journal of Economics, 32: 129-151

[41] Lanjouw, Jean and Mark Schankerman (2004), "Protecting Intellectual Property Rights: Are Small Firms Handicapped?" Journal of Law and Economics, 47: 45-74

[42] Lanjouw, Jean and Mark Schankerman (2004), "Patent Quality and Research Productivity: Measuring Innovation with Multiple Indicators," Economic Journal, 114: 441-465.

[43] Lemley, Mark and Carl Shapiro (2007), "Patent Hold-Up and Royalty Stacking," Texas Law Review 85: 1991-2049

[44] Lerner, Josh and Jean Tirole (2004), "Efficient Patent Pools," American Economic Review, 94: $691-711$

[45] Levin, Richard, Alvin Kievorick, Richard Nelson and Sidney Winter (1987), "Appropriating the returns from industrial R\&D," Brookings Papers on Economic Activity, 3: 783-820

[46] Li, Danielle (2012) "Expertise vs. Bias in Evaluation: Evidence from the NIH," working paper Northwestern University

[47] Maestas, Nicole, Kathleen Mullen, and Alexander Strand (2013), "Does Disability Insurance Receipt Discourage Work? Using Examiner Assignment to Estimate Causal Effects of SSDI Receipt," American Economic Review, 103: 1797-1829

[48] Mokyr, Joel (2002), The Gifts of Athena: Historical Origins of the Knowledge Economy (Princeton: Princeton University Press)

[49] Moser, Petra (2005), "How Do Patent Laws Influence Innovation? Evidence from Nineteenth-Century World's Fairs", American Economic Review 95: 1214-1236

[50] Moser, Petra and Paul Rhode (2011), "Did plant patents create the American rose?," NBER working paper 16983 
[51] Murray, Fiona and Scott Stern (2007), "Do formal intellectual property rights hinder the free flow of scientific knowledge? An empirical test of the anti-commons hypothesis," Journal of Economic Behavior and Organization, 63: 648-687

[52] Murray, Fiona, Philippe Aghion, Mathias Dewatrapont, Julian Kolev and Scott Stern (2008), "Of Mice and Academics: The Role of Openness in Science," MIT Sloan Working Paper

[53] Rivers, Douglas and Quang Vuong (1998), "Limited Information Estimators and Exogeneity Tests for Simultaneous Probit Model," Journal of Econometrics, 39: 347-65

[54] Rosenberg, Nathan (1976), Perspectives on Technology (Cambridge: Cambridge University Press)

[55] Schankerman, Mark and Ariel Pakes (1986), "Estimates of the Value of Patent Rights in European Countries during the Post-1950 Period," Economic Journal, 96: 1052-1076

[56] Serrano, Carlos (2010), "The Dynamics of the Transfer and Renewal of Patents," RAND Journal of Economics, 41: 686-708.

[57] Williams, Heidi (2013), "Intellectual Property Rights and Innovation: Evidence from the Human Genome," Journal of Political Economy, 121: 1-27

[58] Wooldridge, Jeffrey (2002), Econometric Analysis of Cross-Section and Panel Data (Cambridge: MIT Press)

[59] Ziedonis, Rosemarie (2004), "Don't Fence Me In: Fragmented Markets for Technology and the Patent Acquisition Strategies of Firms," Management Science, 50, 804-820 
Table 1. Summary Statistics

\begin{tabular}{|c|c|c|c|c|}
\hline & Mean & Std. Dev. & Min & Max \\
\hline Invaliditated & 0.39 & 0.49 & 0 & 1 \\
\hline PostCites & 8.70 & 19.61 & 0 & 409 \\
\hline PostSelfCites & 0.63 & 4.02 & 0 & 83 \\
\hline PreCites & 21.88 & 45.99 & 0 & 789 \\
\hline PreSelfCites & 1.90 & 6.02 & 0 & 109 \\
\hline Claims & 17.48 & 20.47 & 1 & 244 \\
\hline Patent Age & 9.91 & 5.15 & 1 & 30 \\
\hline \multicolumn{5}{|c|}{$\begin{array}{l}\text { NOTES: Sample of } 1357 \text { Federal Circuit patent invalidity decisions for period 1983-2008. Invalidated=1 if Federal } \\
\text { Circuit invalidates at least one claim of focal patent. PostCites = cites from patents of other assignees in } 5 \text { year } \\
\text { window after Federal Circuit decision. PostSelfCites }=\text { cites from patents owned by same patentee of focal patent } \\
\text { in } 5 \text { year window after Federal Circuit decision. PreCites = cites from patents of other assignees received before } \\
\text { Federal Circuit decision. PreSelfCites = cites received from patents owned by same patentee of focal patent } \\
\text { before Federal Circuit decision. Claims = total number of claims listed in focal patent. Patent age = age in years } \\
\text { from filing date of patent at Federal Circuit decision. }\end{array}$} \\
\hline
\end{tabular}


Table 2. Comparison of Federal Circuit and other Patents

\begin{tabular}{|c|c|c|c|}
\hline & $\begin{array}{c}\text { All Granted Patents not } \\
\text { Litigated }\end{array}$ & $\begin{array}{l}\text { Litigated at Lower Courts } \\
\text { and Not Appealed }\end{array}$ & $\begin{array}{l}\text { Litigated at Lower } \\
\text { Courts and Appealed }\end{array}$ \\
\hline Number of patents & $1,808,770$ & 7,216 & 877 \\
\hline \multicolumn{4}{|l|}{ Technology Field Composition (\%) } \\
\hline Drugs and Medical & 9.2 & 12.1 & 25.7 \\
\hline Chemicals & 19.2 & 11.9 & 12.7 \\
\hline Computers and Communication & 12.5 & 11.9 & 12.4 \\
\hline Electronics & 17.5 & 11.6 & 9.8 \\
\hline Mechanicals & 21.3 & 20.1 & 15.6 \\
\hline Others & 20.4 & 32.5 & 23.8 \\
\hline \multicolumn{4}{|l|}{ Patent Characteristics } \\
\hline Cites received per claim & 1.0 & 1.9 & 2.3 \\
\hline Number of claims & 12.5 & 17.1 & 19.0 \\
\hline Generality & 0.45 & 0.49 & 0.49 \\
\hline Originality & 0.36 & 0.39 & 0.40 \\
\hline \multicolumn{4}{|c|}{$\begin{array}{l}\text { NOTES: Cites }=\text { total citations received up to } 2002 \text {. Number of claims }=\text { total number of claims listed in focal patent. Generality }=1 \\
\text { minus the Herfindahl concentration index of the share of citations received by the focal patents from different patent classes. } \\
\text { Originality }=1 \text { minus the Herfindahl concentration index of the share of citations made by the focal patents in different patent } \\
\text { classes. To perform this comparison, we use litigation data from Lanjouw and Schankerman (2001) and the NBER patent dataset. } \\
\text { Because the lower court litigation data are available only up to } 1999 \text {, we focus on patents granted during } 1980-1999 \text {. Of the } \\
1,816,863 \text { patents granted by the USPTO in this period, } 8,093 \text { are litigated ( } 0.45 \text { percent) and } 877 \text { are involved in Federal Circuit } \\
\text { invalidity decisions ( } 0.05 \text { percent). }\end{array}$} \\
\hline
\end{tabular}


Table 3. Composition of Judge Panels and Patent Invalidation

\begin{tabular}{|c|c|c|c|c|}
\hline & 1 & 2 & 3 & 4 \\
\hline Estimation Method & Probit & Probit & Probit & OLS \\
\hline Dependent Variable & Invalidated & Invalidated & Invalidated & JIP \\
\hline Judges dummies & YES $* * *$ & & & \\
\hline Judges Invalidity Propensity (JIP) & & $\begin{array}{c}3.464 * * * \\
(0.647)\end{array}$ & $\begin{array}{c}3.313^{* * *} \\
(0.743)\end{array}$ & \\
\hline $\log ($ Claims) & $\begin{array}{c}0.034 \\
(0.039)\end{array}$ & & $\begin{array}{c}0.041 \\
(0.039)\end{array}$ & $\begin{array}{l}-0.001 \\
(0.001)\end{array}$ \\
\hline $\log$ (PreCites) & $\begin{array}{c}-0.134^{* * *} \\
(0.041)\end{array}$ & & $\begin{array}{c}-0.137^{* * *} \\
(0.040)\end{array}$ & $\begin{array}{c}0.001 \\
(0.002)\end{array}$ \\
\hline $\log$ (PreSelfCites) & $\begin{array}{c}0.008 \\
(0.0047)\end{array}$ & & $\begin{array}{c}0.002 \\
(0.045)\end{array}$ & $\begin{array}{c}0.002 \\
(0.002)\end{array}$ \\
\hline Year Effects & YES $* * *$ & NO & YES*** & YES*** \\
\hline Age Effects & YES & NO & YES & YES \\
\hline Tech. Effects & YES & NO & YES & YES \\
\hline Fed. Circuit Decisions & 1357 & 1357 & 1357 & 1357 \\
\hline
\end{tabular}


Table 4. Impact of Invalidation on Citations

\begin{tabular}{|c|c|c|c|c|}
\hline & 1 & 2 & 3 & 4 \\
\hline Estimation Method & OLS & IV & IV & IV \\
\hline Dependent Variable & $\log$ (PostCites) & $\log$ (PostCites) & $\log$ (PostCites) & $\log$ (PostTotalCites) \\
\hline \multirow[t]{2}{*}{ Invalidated } & -0.053 & $1.158^{* *}$ & $0.410^{* *}$ & $0.413^{* *}$ \\
\hline & $(0.046)$ & $(0.489)$ & (0.196) & (0.198) \\
\hline \multirow[t]{2}{*}{$\log$ (Claims) } & -0.001 & -0.018 & -0.007 & -0.008 \\
\hline & $(0.025)$ & $(0.030)$ & $(0.025)$ & $(0.025)$ \\
\hline \multirow[t]{2}{*}{$\log$ (PreCites) } & $0.538 * * *$ & $0.598 * * *$ & $0.558 * * *$ & $0.550 * * *$ \\
\hline & $(0.028)$ & $(0.040)$ & $(0.029)$ & $(0.029)$ \\
\hline \multirow[t]{2}{*}{$\log$ (PreSelfCites) } & $0.085^{* *}$ & $0.084^{* *}$ & $0.085^{* *}$ & $0.170^{* *}$ \\
\hline & $(0.030)$ & $(0.034)$ & $(0.030)$ & $(0.031)$ \\
\hline Year Effects & YES*** & YES*** & YES*** & YES*** \\
\hline Age Effects & YES*** & YES*** & YES*** & YES*** \\
\hline Tech. Effects & YES & YES & YES & YES \\
\hline Instrument & & JIP & $\begin{array}{l}\text { predicted probability } \\
\text { from probit }\end{array}$ & $\begin{array}{l}\text { predicted probability } \\
\text { from probit }\end{array}$ \\
\hline IV Tect & & $F=17.43$ & $F=94.85$ & $F=86.18$ \\
\hline IV lest & & $(p<0.01)$ & $(p<0.01)$ & $(p<0.01)$ \\
\hline Fed. Circuit Decisions & 1357 & 1357 & 1357 & 1357 \\
\hline
\end{tabular}

NOTES: ${ }^{*}$ significant at 10 percent, ${ }^{* *}$ significant at 5 percent and ${ }^{* * *}$ significant at 1 percent. Robust standard errors are reported in parentheses PostCites $=$ cites from patents of other assignees in 5 year window after Federal Circuit decision. PostTotalCites $=$ sum of self-cites and cites from patents of other assignees in 5 year window after Federal Circuit decision. Invalidated=1 if Federal Circuit invalidates at least one claim of focal patent. PreCites $=$ cites from patents of other assignees received before Federal Circuit decision. PreSelfCites = cites received from patents owned by same patentee of focal patent before Federal Circuit decision. Claims = total number of claims listed in focal patent. Age = age in years from filing date of patent at Federal Circuit decision. Year=year of Federal Circuit Decision. Technology fields 6 categories defined in Hall et al (2001). JIP= propensity to vote for patent invalidity of judge panel constructed from invalidity votes of judges in other sample cases. IV test is Stock and Yogo (2005) weak ID test. We add one to all citation measures to include patents with no cites. 
Table 5. Impact of Invalidation and Patent Age (IV Estimates)

\begin{tabular}{lcccc}
\hline Sample & $\mathbf{1}$ & $\mathbf{2}$ & $\mathbf{3}$ & $\mathbf{4}$ \\
Age $<=20$ & Age $<=18$ & Age $<=15$ & Age $>15$ \\
Dependent Variable & $\log$ (PostCites) & $\log$ (PostCites) & $\log$ (PostCites) & $\log$ (PostCites) \\
& & & & \\
\hline \hline & & & & \\
Invalidated & $0.412^{* *}$ & $0.457^{* *}$ & $0.577^{* *}$ & 0.055 \\
& $(0.203)$ & $(0.216)$ & $(0.239)$ & $(0.272)$ \\
Fed. Circuit Decisions & 1313 & 1245 & 1098 & 259
\end{tabular}

NOTES: * significant at 10 percent, ${ }^{* *}$ significant at 5 percent and ${ }^{* * *}$ significant at 1 percent. Robust standard errors are reported in parentheses. All regressions control for $\log ($ PreCites), $\log$ (PreSelfCites), $\log (\mathrm{Claims})$, age, technology and year effects. PostCites $=$ cites from patents of other assignees in 5 year window after Federal Circuit decision. Invalidated=1 if Federal Circuit invalidates at least one claim of focal patent. Invalidated is instrumented by the Probit estimates of the probability of invalidation. We add one to all citation measures to include patents with no cites. 
Table 6. Effect of Complexity and Concentration (IV Estimates)

\begin{tabular}{|c|c|c|c|c|c|}
\hline & 1 & 2 & 3 & 4 & 5 \\
\hline Sample & Conc4 >= Median & Conc4 < Median & $\begin{array}{c}\text { Complex } \\
\text { Technologies }\end{array}$ & $\begin{array}{l}\text { Non Complex } \\
\text { Technologies }\end{array}$ & Full \\
\hline Dependent Variable & $\log$ (PostCites) & $\log$ (PostCites) & $\log$ (PostCites) & $\log$ (PostCites) & $\log$ (PostCites) \\
\hline Invalidated & $\begin{array}{c}0.086 \\
(0.331)\end{array}$ & $\begin{array}{c}0.985^{* * *} \\
(0.288)\end{array}$ & $\begin{array}{c}0.739 * * \\
(0.322)\end{array}$ & $\begin{array}{l}0.317^{*} \\
(0.183)\end{array}$ & $\begin{array}{c}0.557^{* *} \\
(0.263)\end{array}$ \\
\hline Invalidated x Conc4 & & & & & $\begin{array}{c}-6.977 * * * \\
(2.457)\end{array}$ \\
\hline Invalidated x Complex & & & & & $\begin{array}{l}1.234^{* * *} \\
(0.327)\end{array}$ \\
\hline Fed. Circuit Decisions & 678 & 677 & 437 & 920 & 1357 \\
\hline
\end{tabular}

NOTES: * significant at 10 percent, ${ }^{* *}$ significant at 5 percent and ${ }^{* * *}$ significant at 1 percent. Robust standard errors are reported in parentheses. All regressions control for $\log ($ PreCites), $\log ($ PreSelfCites $), \log ($ Claims ), age and year effects. PostCites = cites from patents of other assignees in 5 year window after Federal Circuit decision. Invalidated=1 if Federal Circuit invalidates at least one claim of focal patent. Columns 1, 2, and 5 controls for technology class effects. Column 5 also controls for the direct effect of Conc4. Complex=1 if patent is in Computer and Communication (NBER Category 2), Electrical and Electronics (NBER Category 4), Medical Instruments (NBER subcategory 32), and Biotechnology (NBER subcategory 33). Conc4 is the patenting share of the four largest assignees in the technol ogy subcategory of the litigated patent during the five years preceding the Federal Circuit decision. Invalidated and its interactions are instrumented by the Probit estimates of the probability of invalidation and its interactions. We add one to all citation measures to include patents with no cites. 
Table 7. Technology Differences in Invalidation Effect (IV Estimates)

\begin{tabular}{lcc}
\hline Technology & Based on Complex and Conc4 & Split Sample \\
\hline \hline & & \\
Chemical & -0.028 & -0.710 \\
& $(0.242)$ & $(0.725)$ \\
Mechanical & 0.173 & -0.225 \\
& $(0.230)$ & $(0.519)$ \\
Drugs & & \\
& 0.229 & 0.231 \\
Computers & $(0.230)$ & $(0.449)$ \\
and Communications & & $2.388^{* *}$ \\
Electrical and Electronics & $1.024 * * *$ & $(1.224)$ \\
& $(0.285)$ & -2.744 \\
Medical Instruments & $1.107^{* * *}$ & $(2.339)$ \\
and Biotechnology & $(0.285)$ & \\
& $1.435^{* * *}$ & $2.402 * * *$ \\
\hline
\end{tabular}

NOTES: * significant at 10 percent, ${ }^{* *}$ significant at 5 percent and ${ }^{* * *}$ significant at 1 percent. Robust standard errors are reported in parentheses. Estimates in column 1 obtained from column 5 of Table 6 and sample means of Conc 4 across various technology areas. Each regression in column 2 controls for $\log$ (PreCites), $\log$ (PreSelfCites), $\log$ (Claims), age and year effects. PostCites = cites from patents of other assignees in 5 year window after Federal Circuit decision. Invalidated=1 if Federal Circuit invalidates at least one claim of focal patent. Invalidated instrumented by the Probit estimates of the probability of invalidation. We add one to all citation measures to include patents with no cites. 
Table 8. Intensive and Extensive Margins (IV Estimates)

\begin{tabular}{|c|c|c|c|c|c|c|c|c|c|}
\hline \multirow[t]{3}{*}{ Dependent Variable } & \multicolumn{3}{|c|}{$\begin{array}{l}\text { Total Effect } \\
\log (\text { PostCites) }\end{array}$} & \multicolumn{3}{|c|}{$\begin{array}{c}\text { Extensive Margin } \\
\log (\text { Number of distinct Assignees) }\end{array}$} & \multicolumn{3}{|c|}{$\begin{array}{c}\text { Intensive Margin } \\
\text { log(PostCites per Assignee) }\end{array}$} \\
\hline & 1 & 2 & 3 & 4 & 5 & 6 & 7 & 8 & 9 \\
\hline & $\begin{array}{l}\text { Citing Patents } \\
\text { in Small } \\
\text { Portfolios }\end{array}$ & $\begin{array}{l}\text { Citing Patents } \\
\text { in Medium } \\
\text { Portfolios }\end{array}$ & $\begin{array}{l}\text { Citing Patents } \\
\text { in Large } \\
\text { Portfolios }\end{array}$ & $\begin{array}{l}\text { Citing Patents } \\
\text { in Small } \\
\text { Portfolios }\end{array}$ & $\begin{array}{l}\text { Citing Patents } \\
\text { in Medium } \\
\text { Portfolios }\end{array}$ & $\begin{array}{l}\text { Citing Patents } \\
\text { in Large } \\
\text { Portfolios }\end{array}$ & $\begin{array}{l}\text { Citing Patents } \\
\text { in Small } \\
\text { Portfolios }\end{array}$ & $\begin{array}{c}\text { Citing Patents in } \\
\text { Medium } \\
\text { Portfolios }\end{array}$ & $\begin{array}{l}\text { Citing Patents } \\
\text { in Large } \\
\text { Portfolios }\end{array}$ \\
\hline Invalidated & $\begin{array}{c}0.075 \\
(0.183)\end{array}$ & $\begin{array}{c}0.190 \\
(0.168)\end{array}$ & $\begin{array}{c}0.228 \\
(0.158)\end{array}$ & $\begin{array}{c}0.036 \\
(0.155)\end{array}$ & $\begin{array}{c}0.003 \\
(0.105)\end{array}$ & $\begin{array}{c}0.123 \\
(0.104)\end{array}$ & $\begin{array}{c}0.025 \\
(0.053)\end{array}$ & $\begin{array}{c}0.171 \\
(0.105)\end{array}$ & $\begin{array}{c}0.088 \\
(0.079)\end{array}$ \\
\hline $\begin{array}{l}\text { Invalidated X } \\
\text { Large Patentee }\end{array}$ & $\begin{array}{l}1.840 * * \\
(0.726)\end{array}$ & $\begin{array}{c}0.826 \\
(0.663)\end{array}$ & $\begin{array}{c}0.689 \\
(0.837)\end{array}$ & $\begin{array}{l}1.347^{* *} \\
(0.556)\end{array}$ & $\begin{array}{c}0.418 \\
(0.376)\end{array}$ & $\begin{array}{c}0.041 \\
(0.446)\end{array}$ & $\begin{array}{l}0.479^{*} \\
(0.261)\end{array}$ & $\begin{array}{c}0.362 \\
(0.393)\end{array}$ & $\begin{array}{c}0.659 \\
(0.535)\end{array}$ \\
\hline
\end{tabular}

NOTES: * significant at 10 percent, ${ }^{* *}$ significant at 5 percent and ${ }^{* * *}$ significant at 1 percent. Robust standard errors are reported in parentheses. All regressions control for log(PreCites) in the size group, $\log ($ PreSelfCites), $\log (\mathrm{Claims})$, age and year effects. PostCites = cites from patents of other assignees in 5 year window after Federal Circuit decision. Invalidated=1 if Federal Circuit invalidates at least one claim of focal patent. Invalidated and its interactions are instrumented by the Probit estimates of the probability of invalidation and its interactions. Large Patentee $=1$ if patentee has more than 102 patents. A citing firm is classified as small if its portfolio has less than 5 patents, as medium if the portfolio has between 5 and 102 patents and as large if it has more than 102 patents. Dependent variables: in columns 1-3 are the total external cites received by the patent from citing firms in the size group, in columns $4-6$ are the total number of citing firms in the size group and columns 7-9 are the external cites per assignee in the size group. We add one to all citation measures to include patents with no cites. 
Table 9. Measuring Follow-on Innovation with Non-Patent Data (IV Estimates)

\section{A. Medical Instruments}

(1) (2) (3)

\begin{tabular}{lccc} 
Dependent Variable & $\log$ (PostCites) & $\begin{array}{c}\log \text { (Post FDA Approvals) } \\
\text { keyword match }\end{array}$ & $\begin{array}{c}\log \text { (Post FDA Approvals) } \\
\text { product class match }\end{array}$ \\
\hline \hline Invalidated & $2.447^{*}$ & $1.161^{*}$ & $1.516^{* *}$ \\
& $(1.264)$ & $(0.621)$ & $(0.725)$ \\
Fed. Circuit Decisions & 121 & 121 & 121
\end{tabular}

\section{B. Drugs}

(1)

\begin{tabular}{lccc} 
Dependent Variable & $\log$ (PostCites) & $\begin{array}{c}\log \text { (PostClinicalTrials) } \\
\text { identified drugs }\end{array}$ & $\begin{array}{c}\log \text { (PostClinicalTrials) } \\
\text { keyword match }\end{array}$ \\
\hline \hline Invalidated & 0.231 & 0.266 & 0.539 \\
& $(0.449)$ & $(1.269)$ & $(1.200)$ \\
Fed. Circuit Decisions & 167 & 94 & 140
\end{tabular}

NOTES: ${ }^{*}$ significant at 10 percent, ${ }^{* *}$ significant at 5 percent and ${ }^{* * *}$ significant at 1 percent. Robust standard errors are reported in parentheses. All regressions control for $\log ($ PreCites), $\log ($ PreSelfCites), age and year effects. Invalidated=1 if Federal Circuit invalidates at least one claim of focal patent. Post FDA Approvals= number of approval requests to Food and Drug Administration related to focal patent in 5 year window following Fed. Circuit decision. PostClinicalTrials = number of clinical trials related to focal patent in 5 year window following Fed. Circuit decision. We add one to all innovation measures to include observations with a value equal to zero. 
Table 10. Technology Substitution and Media Coverage (IV Estimates) 1 2 3

Invalidated

$-0.053$

(0.112)

$-0.169 *$

(0.101)

$-0.144$

(0.092)

$0.404^{* *}$

(0.196)

0.007

(0.008)

MediaMention

Sample
Fed. Circuit Decisions

One Related

Patent
Two Related
Patents
1024

Three Related

Patents

1119
Full

NOTES: * significant at 10 percent, ${ }^{* *}$ significant at 5 percent and $* * *$ significant at 1 percent. Robust standard errors are reported in parentheses. All regressions control for $\log ($ PreCites), $\log$ (PreSelfCites), $\log (\mathrm{Claims})$, age, technology and year effects. PostCites = cites from patents of other assignees in 5 year window after Federal Circuit decision. Invalidated=1 if Federal Circuit invalidates at least one claim of focal patent. MediaMention is equal to the number of FACTIVA articles referring to case during one year window centered on the decision date. In column 1 the sample includes the highest ranked Google match for each of the Federal Circuit patents for which a related patent was identified. In columns 2 (and 3) the sample focuses on the top two (three) highest ranked matches for the Federal Circuit patents where at least two matches were identified. We add one to all citation measures to include patents with no cites. 


\section{Figure 1. Patent Protection and Follow-on Innovation}

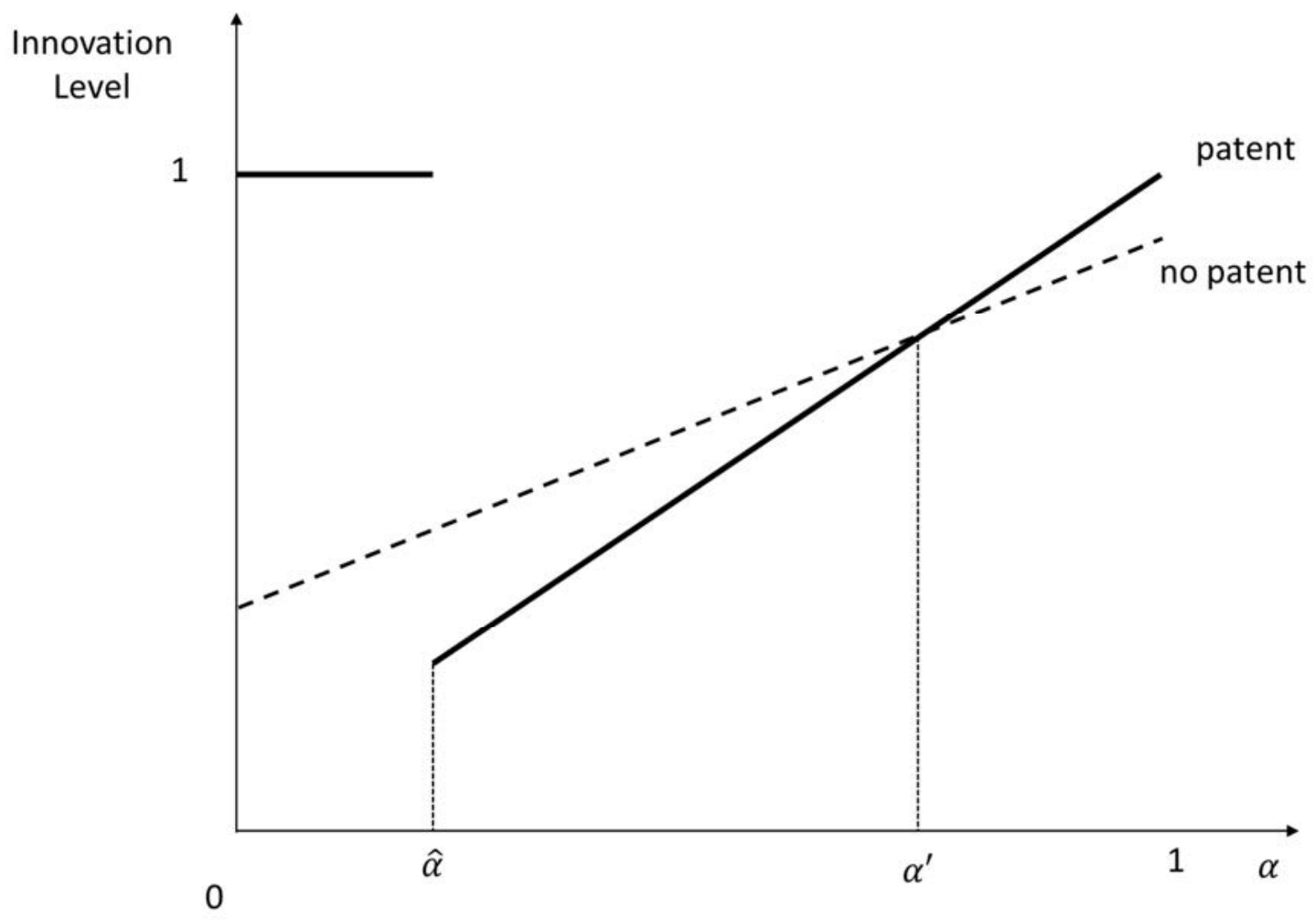

NOTES: The figure plots the level of expected follow-on innovation in the case in which the upstream technology is protected by a patent (solid line) and in the case in which there is not protection (dashed line). The parameter $\alpha$ denotes the probability that the follow-on technology has high value. 
Figure 2. Timing of the Invalidation Effect

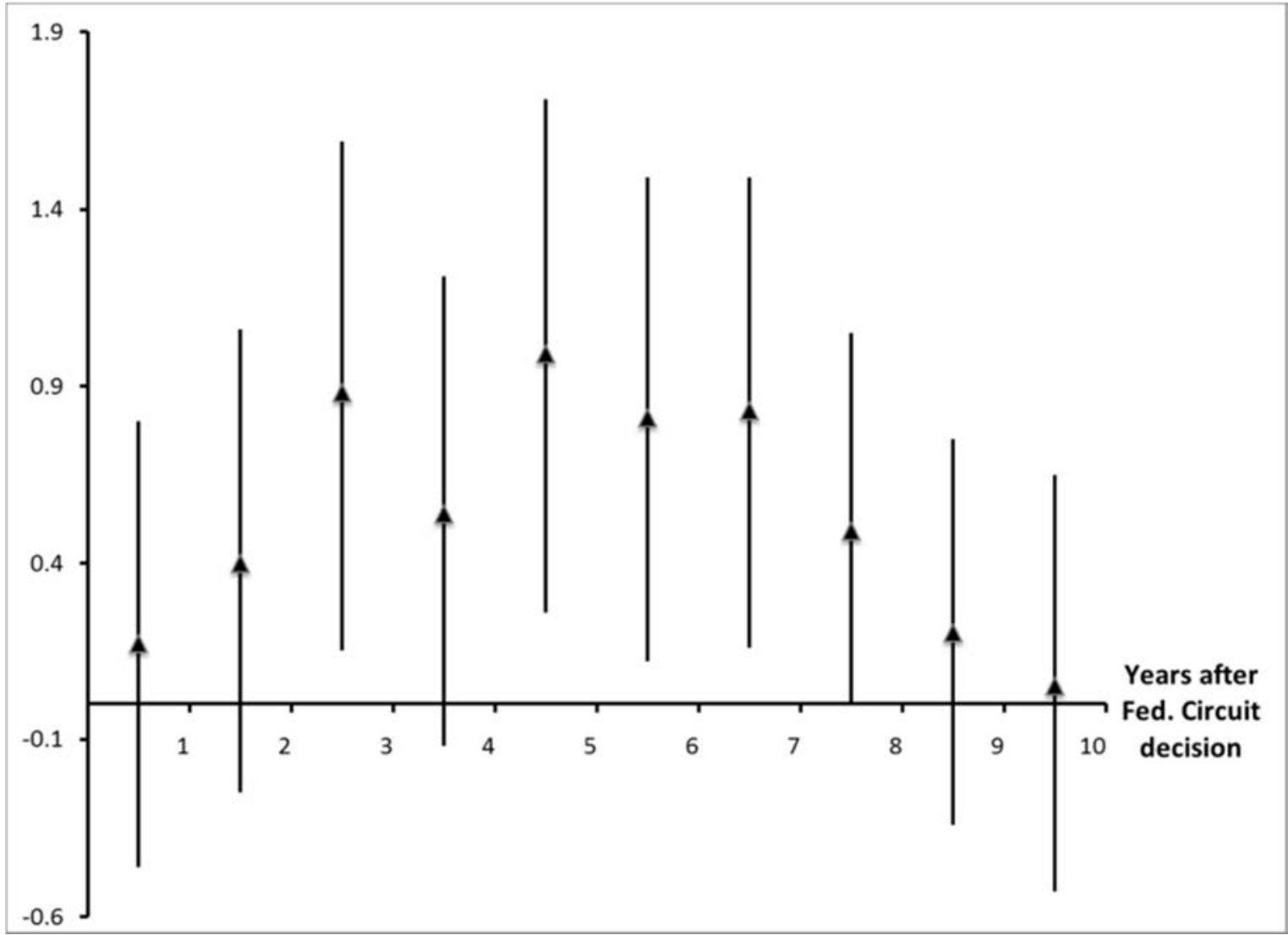

NOTES: IV estimate of the invalidation effects and 90-percent confidence intervals in each of the ten years following invalidation. 
Figure 3. Marginal Treatment Effect

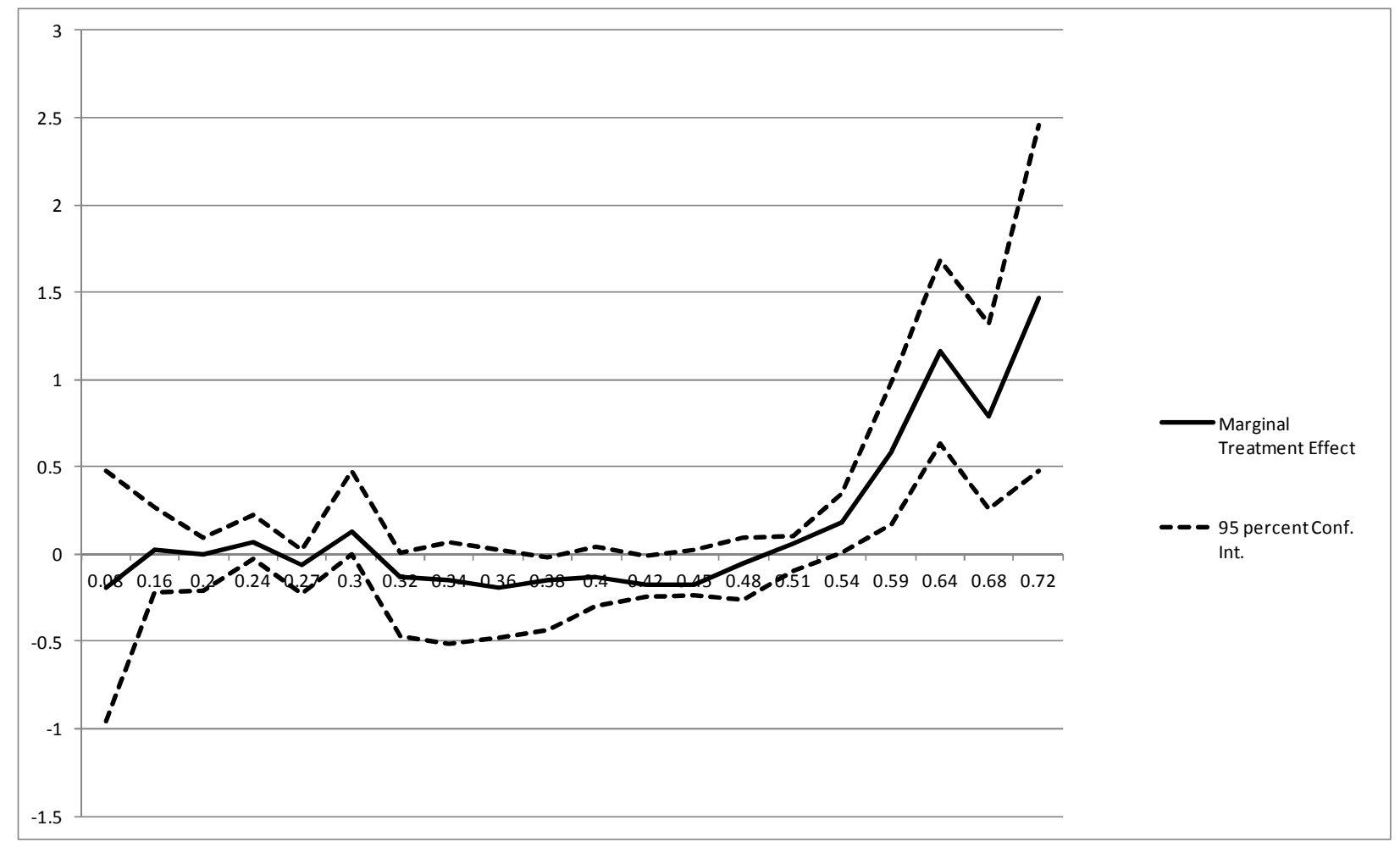

NOTES: The horizontal axis indicates the estimated probability that the patent is invalidated. The vertical axis shows the effect of invalidation on post-decision citations for different values of invalidation probability. 


\title{
ONLINE APPENDIX \\ Patents and Cumulative Innovation: Causal Evidence from the Courts
}

\author{
Alberto Galasso \\ Mark Schankerman \\ University of Toronto and NBER London School of Economics and CEPR
}




\section{Microfounding the JIP Measure}

We develop a simple model of strategic voting, closely following Feddersen and Pesendorfer (1996). There are three judges $i \in\{1,2,3\}$ who must decide whether a patent is valid $(V)$ or not invalid $(N)$. Judges are uncertain about the validity of the patent and each judge gets a signal $v$ or $n$ that is correlated with the true state. Specifically we assume that

$$
\operatorname{Pr}(v \mid V)=\operatorname{Pr}(n \mid N)=p_{i}
$$

The parameter $p_{i} \in[\underline{p}, \bar{p}]$ with $.5<\underline{p}<\bar{p}<1$ is the probability that a judge receives the correct signal. The parameter $p_{i}$ can be interpreted as the 'complexity' of the case for judge $i$. The assumption that the signals are private information is standard in the literature on voting. Feddersen and Pesendorfer (1996) provide a number of reasons why the complete disclosure of private information may not occur. For example, some judges may have technical knowledge that is relevant for the case but difficult to communicate. Moreover, differences in preferences for patent validity may reduce the incentives to reveal private information in deliberations.

The judges vote simultaneously either to validate or invalidate and the decision is taken by majority voting. There are two outcomes: either the patent is invalidated (1) or not (0). We assume that each judge maximizes her expected utility and that preferences are given by $u(1, N)=u(0, V)=0$ and $u(1, V)=-q_{i}$ and $u(0, N)=-\left(1-q_{i}\right)$. The parameter $q_{i}$ characterizes the judge's threshold of reasonable doubt. Let $\beta_{i}(n)$ denote the posterior probability for judge $i$ that the patent is invalid, conditional on obtaining an invalidity signal and being pivotal, i.e that the other two judges, $x$ and $z$, receive different signals from each other. Let $\beta_{i}(v)$ denote the posterior probability for judge $i$ that the patent is invalid, conditional on obtaining a validity signal and being pivotal:

$$
\begin{aligned}
& \beta_{i}(n)=\frac{p_{i}\left(1-p_{x}\right) p_{z}}{p_{i}\left(1-p_{x}\right) p_{z}+\left(1-p_{i}\right)\left(1-p_{x}\right) p_{z}}=p_{i} \\
& \beta_{i}(v)=\frac{\left(1-p_{i}\right)\left(1-p_{x}\right) p_{z}}{p_{i}(1-p) p_{z}+\left(1-p_{i}\right)\left(1-p_{x}\right) p_{z}}=1-p_{i} .
\end{aligned}
$$

We assume that $\beta_{i}(v)<q_{i}<\beta_{i}(n)$ for each $i$. Feddersen and Pesendorfer (1996) show that if this assumption is satisfied each judge in equilibrium will vote according to his signal (i.e., what they call 'informative' voting). More specifically, a pivotal judge receiving an invalidity signal will vote for invalidity as long as her expected utility is higher from doing so:

$$
\beta_{i}(n) 0-\left(1-\beta_{i}(n)\right) q_{i} \geq\left(1-\beta_{i}(n)\right) 0-\beta_{i}(n)\left(1-q_{i}\right)
$$


which is satisfied because we assumed $q_{i}<\beta_{i}(n)$. She will also vote for validity if she receives a validity signal because $\beta_{i}(v)<q_{i}$. Moreover, note that $\beta_{i}(v)=1-p_{i}$ and $\beta_{i}(n)=p_{i}$, so the condition for an informative equilibrium is always satisfied as long as $1-\underline{p}<q_{i}<\underline{p}$.

We assume that the complexity of a case, $p_{i}$, is an i.i.d. draw from a distribution $F(p)$ with support $[\underline{p}, \bar{p}]$ and that $1-\underline{p}<q_{i}<\underline{p}$. The ex ante probability that judge $i$ will vote for invalidity will be $1-F\left(q_{i}\right) \equiv f^{i}$ and the expected number of invalidity votes in the three judge panel will be equal to

$$
J I P=f^{1} f^{2} f^{3}+f^{1} f^{2}\left(1-f^{3}\right)+f^{1}\left(1-f^{2}\right) f^{3}+\left(1-f^{1}\right) f^{2} f^{3} .
$$

Given the random allocation of judges to cases, the sample average of a judge's validity votes will be an unbiased estimator of her probability of voting for validity. Moreover, JIP is a consistent estimator of the number of validity votes in the three judge panel (it is not unbiased, as it is a nonlinear transformation of the $f^{i}$ 's).

\section{Randomization and Heterogeneity of Judges: Robustness}

As additional evidence on the randomization of judges to cases, Table A2 reports the correlations between JIP and various subsets of patent characteristics. In each regression we include a control for the year of the Federal Circuit decision. The table confirms that there is no significant correlation between JIP and the patent variables used in our analysis. Moreover, the point estimates of the coefficients are close to zero, indicating that the magnitude of the correlation is very small. Columns (1) to (4) present separate regressions for claims, citations, self-citations and age. In column (5) we present the correlation between the technology dummies and JIP. We cannot reject the hypothesis that the coefficients on the technology field dummies are jointly equal to zero $(p$-value $=0.41)$. In column $(6)$ we regress JIP on all these patent characteristics. We cannot reject the hypothesis that the coefficients on all these variables (except year dummies) are jointly equal to zero ( $p$-value $=$ of 0.73 ). Column (7) shows that we obtain similar results if we replace the linear control for age with a full set of age fixed effects. In this regression we cannot reject that the coefficients on the age dummies are jointly equal to zero $(p$-value $=0.79)$ and the test that the coefficients on all patent characteristics (except year dummies) are zero ( $p$-value $=0.82)$.

We also provide additional evidence on the heterogeneity of the propensity of judges 
to invalidate. Specifically, we show that the estimated variation is inconsistent with a setup in which judge decisions reflect identical voting propensities plus random error. To do this, we construct a counterfactual where judges vote according to the same random process. We generate a simulated judge vote that takes into account the effect of observable patent characteristics on the probability of invalidation. To construct the simulated votes, we use the following procedure. First, we regress the votes of each judge on observable characteristics of the cases, without including judge fixed effects, and then construct the predicted probability of an invalidity vote for each judge $j$ for patent $p$, based on these characteristics, $\phi_{j p}$, and the regression residuals, $e_{j p}$. Second, we add to the probability $\phi_{j p}$ a random draw $\omega_{j p}$ from a normal distribution with mean and standard deviation equal to the mean and standard deviation of the distribution of the regression residuals. Finally, the simulated invalidity vote for judge $j$ for patent $p$ is set equal to one if the sum of the predicted invalidity and the random draw $\left(\phi_{j p}+\omega_{j p}\right)$ is above one. We obtain very similar results using different thresholds. We use the simulated vote to estimate judge fixed effects and find that they are not statistically significant $(p$-value $=0.66)$. In Figure A2 we compare the distribution of these fixed effects from simulated votes with the (statistically significant) fixed effects estimated using actual voting behavior. The difference between the two distributions is striking: the variance of the Federal Circuit fixed effects is much larger than the one we would observe if judges were voting on the basis of identical propensities plus random error.

\section{Effect of Patent Invalidation: Robustness}

In this section we describe a series of robustness checks on our main finding of positive effect of invalidation on follow-on innovation. Estimates for some of these regressions are reported in Table A3.

First, in the text we treated an invalidation judgement as the final verdict. However, parties to the dispute have the right to appeal the decision of the Federal Circuit to the Supreme Court (which retains discretion over whether to hear the case). This means that invalidation of a patent by the Federal Circuit retains some uncertainty, so that downstream innovators whom the patent blocked might not respond until this uncertainty is removed. In our context, this is equivalent to saying that our key variable, Invalidation, contains some measurement error. In theory, any such error should be taken care of by our instrumental variable estimation. 
Nonetheless, as a further check we identified that the patent invalidity cases appealed to the Supreme Court in our data set. Only 23 Federal Circuit decisions were reviewed by the Supreme Court in the period 1982-2008 (Golden, 2009). Only 12 of these cases are in our dataset (the others involve issues other than patent validity).We drop these cases and re-estimate the model (by IV). In column 1 of Table A3 we show that the estimated effect is very close to the baseline coefficient of 0.410 .

Second, the baseline model incorporates fixed effects for six broad (one-digit) technology fields. We also estimate a specification which uses a more refined technology classification - 32 two-digit subcategories from the NBER. Column 2 of Table A3 shows that the point estimate of the coefficient on Invalidation is nearly double the baseline estimate but less precise, 0.915 (standard error $=0.422$ ), and we cannot reject the null hypothesis that the two estimated coefficients are the same $(p$-value $=0.11)$. In the paper we retain the one-digit technology field dummies. We do this because the empirical analysis often involves using smaller subsamples split along various dimensions. As a robustness check, we re-estimate all of those regressions using the more detailed, two-digit technology field dummies and obtain qualitatively (and in most cases, quantitatively) similar results, but the estimates are less precise.

Third, the citations information obtained from the USPTO ends in 2010, so the latest years in the sample are subject to truncation. Moreover, citations are obtained from a dataset of patent grants (but note that they are linked to litigated patents using the application date) - this is always the case using the USPTO - and this may potentially amplify the truncation concerns. We run a series of robustness checks to assess whether truncation is an issue in our study. First, while our baseline specification controls for year effects and these mitigate the truncation problem, there may be concern that the truncation problems differ by technology field since citation patterns vary. To address this, in Table A3 we introduce interactions between the year and technology category dummy variables to allow truncation effects to be different across technology classes. Column 3 shows that the coefficient on invalidity is very similar to the one estimated in the baseline. Column 4 restricts the sample to patent decisions that take place before 2003, for which we have a complete 5-year time window of citations and thus expect truncation to be less severe. Results are robust and the coefficient on invalidity is slightly larger than, but not statistically different from, the one in our baseline regression. We also estimate the invalidity effect focusing on patents litigated before 2000. This is equivalent 
to dropping about half of the sample. Also in this case the result is robust and the coefficient is equal to 0.361 ( std. error $=0.158)$, which is very similar to our baseline estimate.

As a complementary approach to correct more directly for truncation, we adjusted citation totals for Federal Circuit decisions in which we observe only a portion of the five year post-decision interval. To perform this correction, we exploit the "quasi-structural" citation lag distribution estimated in Hall, Jaffe and Trajtenberg (2001). They provide an estimate of the distribution of citations received over the life of patents across different technology classes. ${ }^{1}$ Their estimates allow us to inflate the citations received by patents for which we observe only a fraction of the five year window, taking into account the propensity of patents in that technology field to be cited at the specific age in which data are missing.

This correction generates a negligible increase in the sample average of the citations received in the five years after invalidation (from 8.70 to 8.77 ). Nonetheless, for patents with truncated post-decision windows, the average external cites received increase by 40 percent (from 1.08 to 1.52 ), which highlights the impact of truncation. Nonetheless, in column 5, we show that replacing our main citation measure with the truncation-adjusted measure does not affect our baseline results. The estimated coefficient is 0.437 , which is only slightly larger than the one estimated in our baseline regression. As an additional test, we exploit the estimates by Hall, Jaffe and Trajtenberg (2001) to inflate the citations received in the five year window after invalidation in order to obtain a predicted 10-year post-decision citations total for each patent. Not surprisingly, with this correction, the sample average of post-decision citations increases substantially, from 8.70 to 14.76 . Nonetheless, the estimated impact of invalidation is robust - using this measure, the estimated coefficient is 0.460 (standard error $=0.229$ ). The estimated effect based on the post-decision 10-year window is very similar to the one estimated for the five year window when we adjust for truncation. This is consistent with our finding in the paper on the timing of the effect - where we estimated that most of the effect takes place in the third to sixth years following invalidation.

Fourth, one may be concerned that citations have a geographic component and the effect of invalidation could be different for foreign and domestic patentees (remember that all our

\footnotetext{
${ }^{1}$ The estimates are made under the assumptions of (i) proportionality (the shape of the distribution is independent of the total number of citations received), (ii) stationarity (the distribution does not depend on the cohort of the patent) and (iii) patents do not received citations after 35 years of age.
} 
sample patents are in the U.S.). There are at least two reasons why the effect of invalidation of a patent in the U.S. might affect foreign follow-on innovators less strongly. First, if licensing barriers represent only a small fraction of the overall costs associated with entry into the U.S. market, removal of patent protection may not have a major impact on the decisions of later foreign innovators. Second, the patent in the U.S. confers protection only in the U.S., while the decision to innovate depends on profits that can earned in the global market. Thus the impact of invalidation of the U.S. patent will depend on the relative importance of the U.S. market to the follow-on innovators and this may differ for domestic and foreign innovators.

To address this concern empirically, we exploit the USPTO assignee type codes information and constructed new measures that distinguish between citations originating from domestic (U.S.) innovators citations and foreign innovators and then examine whether the invalidation effect is different for the two groups. On average, 27 percent of the citations received by the patents in our sample before the Federal Circuit decision belong to foreign innovators. We reestimate our baseline regression using each of these two dependent variables and found that the invalidation effect is exclusively driven by an increase in citations by domestic follow-on innovators. Column 6 in Table A3 shows the estimated effect for subsequent citations by domestic patentees. For citations by foreign owners, the estimated coefficient is an order of magnitude smaller and not statistically significant. This result is consistent with the idea that it is costly

for foreign innovators to patent in U.S. and that licensing frictions represent only a fraction of the total cost sustained (or possibly that the U.S. market is relatively less important for foreign innovators).

\section{Additional Unreported Tests}

Finally, we conduct a set of additional robustness tests that are not reported in Table A3. First, the baseline specification incorporates a full set of patent age fixed effects. However, the age distribution of citations may vary across technology fields (for evidence, Jaffe and Trajtenberg, 2002). To allow for this, we extend the specification by including a full set of interactions between the technology field and age dummies. The estimated coefficient on Invalidation is 0.401 (standard error $=0.192$ ), which is nearly identical to the baseline estimate.

The second robustness check involves how to treat patents that receive no citations before the Federal Court decision (4 percent of the sample) and those that receive no cites in the five year widow after the decision (23 percent of the sample). In our baseline specification we 'fix' 
this problem by using $\log ($ PostCites +1$)$, which is common practice but may introduce bias. We re-estimate the baseline model adding dummy variables for patents that received no cites before the Federal Circuit decision and for patents that receive no cites after the decision. The results are robust - the point estimate on Invalidation is 0.449 (standard error $=0.167$ ). We get similar results if we drop these patents from the sample entirely. We get similar results if we use the number of citations without logarithmic transformation as the dependent variable (once suitably transformed for comparability). Finally, we also estimated a Poisson count model by instrumental variables (using the predicted probability of invalidation $\widehat{P}$ as the instrument). The point estimate is 0.638 (standard error $=0.321$ ) which is larger than, but not statistically different from, the baseline coefficient. In the analysis in the paper, we do not use the Poisson model because the econometric techniques that we use to estimate the heterogenous marginal treatment effect of patent invalidation have only been developed for linear models.

Third, there is a concern that some Federal Circuit decisions may involve rulings that limit the scope of patentable subject matter rather than simply assessing the validity of the focal patent. Such decisions could reduce subsequent citations for the entire technology field, leading us to underestimate the true blocking effect of patent rights. To address this, we identified the most important Federal Circuit decisions that relate to patentable subject matter during our sample period (the main sources are Dolmeage, 2006 and Kappos et. al., 2008). We obtained a list of 14 Federal Circuit decisions that are concentrated in the areas of software, business methods and biotechnology, of which only three are in our sample. There are very few cases in our sample because most of the key Federal Circuit decisions on patentable subject matter do not involve granted patents but only patent applications. Moreover, because of their importance, some of these cases are decided 'en banc' by the entire court and not by a panel of three judges. We excluded such special cases from our sample. Dropping the three decisions that were in our sample and re-estimating the model, we obtain coefficients that are nearly identical to the baseline estimates.

Finally, we examine robustness of our results when controlling for competition in two ways. First, the size of the patentee is likely to shape the levels of product market and technology competition with other firms. We control for the size of the patentee, measured as the size of its patent portfolio (number of patents granted in the five years preceding the Federal Circuit decision) and obtain an estimated invalidation effect that is very similar to the baseline. 
Second, competitive pressure is also likely to depend on the concentration of firms operating in a technology area. Controls for concentration with the share of the four largest patentees (or the Herfindahl index of patent ownership) in the two-digit technology sub-category of the litigated patent yields very similar results.

We also look at the difference in invalidation effect across different samples comprising patents with different level of pre-invalidation citations. To conduct these exercises, we create a new variable equal to the (logarithm) of pre-invalidation citations filtered by age effects, year effects, technology effects, number of claims and pre-invalidation self-citations. We find no evidence of a larger (or smaller) effect of invalidation for patents that receive more preinvalidation (normalized) citations.

\section{Intensive and Extensive Margins: Robustness}

We conduct extensive robustness checks on the regressions in Table 8. We report the estimates for some of these regressions in Table A4. First, we vary the thresholds for defining 'small' firms ( $\leq 1,10$ and 15 patents), and for defining 'large' firms ( $\geq 75,110$ and 150 patents). Second, we re-estimate the effects of patent invalidation by splitting the samples between large and non-large patentees. We also break down the category of non-large patentees into two groups, small and medium sized firms. In all of these experiments, the pattern that emerges in Table 8 is extremely robust. In every case the effect of invalidation is concentrated on the subsequent citations by small innovators to focal patents held by large firms, and it is predominantly an extensive margin effect.

Because of sample size, we cannot allow the effect of invalidation to vary with technology field in these regressions (we do allow for additive field effects, however). If citations from small citers to large patentees are overrepresented in fragmented and complex technology fields, where we found blockage was more likely, our finding that blocking effect of invalidation is limited to the large patentee-small citing firm category could be simply a technology field composition effect. To check this concern, we examined the percent of citations in each technology field accounted for by citations by small to large patentees. The technology fields where invalidation has a statistically significant blocking effect (medical instruments, electronics and computers) are not those with the largest fraction of citations from small to large patentees - the mean fraction of sample citations from small to large patentees is 7.4 percent in these fields, as 
compared to 9.9 percent in the other fields. We conclude that our empirical finding is not due to a technology field composition effect.

\section{Using Non-Patent Data to Measure Follow-on Innovation: Data Construction and Robustness}

\subsection{Medical Instruments}

\section{Data Construction}

Following the Medical Device Amendments Act passed by Congress in 1976, the U.S. Food and Drug Administration (FDA) has primary authority to regulate medical devices sold in U.S. These products are subject to a regulatory process that requires detailed product information and evidence of safety from clinical trials. The FDA releases data on approval requested for medical instruments. We construct a new measure of cumulative innovation by linking FDA approval requests to the medical instrument patents in our sample.

Specifically, there are two types of medical instrument approval processes that can take place at the FDA. The first and more common approval is the 510k premarketing submission made to FDA to demonstrate that the device to be marketed is safe and effective. This procedure is for 'low risk' and 'moderate risk' devices. The second, less common and more stringent approval is the Premarket Approval (PMA) application for 'high risk' devices. The FDA data indicate that, for the period 1981-2013, there were about 125,000 requests for 510k approvals and 26,000 requests for PMA approval.

In our sample of patents litigated at the Federal Circuit, there are 121 cases involving medical devices (NBER sub-categories 32 and 39). To link patents with FDA approval requests, for each patent we identify a set of keywords related to the technology and search for FDA approval requests that contain such keywords. We carefully read the abstract and title of each litigated patent and collected one 'primary' keyword and up to two 'secondary' keywords for each of the patents in our sample. Exploiting these keywords, we construct our first two measures of cumulative innovation. The first one, Approvals_1, is equal to the number of FDA approval requests (PMA and 510k) for which the product name contains the primary keyword. The second one, Approvals_2, is equal to the number of FDA approval requests (PMA and $510 \mathrm{k}$ ) for which the product name contains at least one of the keywords (primary or secondary) of the patent. As in our baseline analysis, the dependent variables are constructed focusing on 
a five year window following the Federal Circuit decision. The regressions control for the total number of applications in the period between the grant of the patent and the Federal Circuit decision, as well as for the other controls employed in our baseline regression.

The correlation between citations received in the five years after the decision and Approvals_1 is 0.3 ; the correlation with Approvals_2 is 0.1 . If we exclude potentially unmatched patents (patents receiving citations before invalidation but that could not be matched to any FDA approval requests), the correlation between cites and Approvals_1 increases to 0.4 and the one between cites and Approvals_2 increases to 0.3.

As a second approach to exploit FDA approval data to measure cumulative innovation, we assign each litigated patent to a set of product codes among the roughly 6,000 product codes in which the FDA classifies medical devices. Also in this case we distinguish between a 'primary' product code and up to two 'secondary' codes. We construct two additional measures of cumulative innovation counting the number of FDA approval requests (PMA and 510k) in the same product code of the litigated patent. The first measure only counts applications in the primary product code, whereas the second one includes primary and secondary product codes. The correlation with the citations received before invalidation is roughly equal to 0.1 for both of these measures of cumulative innovation.

Both measures based on "primary" and "extended" sets of keywords and product classes may be associated with two distinct types of measurement errors. Focusing on primary keywords and product classes may lead to under-counting follow-on innovation, if applications related to the patented technologies do not include the keyword or are in a different product classes. However, enlarging the number of keywords or patents may lead to over-counting follow-on innovation if we include products that are not related to the patented technology.

\section{Results}

Column 2 in Panel A of Table 9 in the paper shows the effect of invalidation using Approvals_2 as dependent variable, the measure constructed exploiting an extended set of keywords. The estimated effect using Approvals_1 as dependent variable, the measure based only on the primary keyword is very similar - the point estimate is 1.116 (standard error $=0.617$ ). Column 3 in the same panel uses the measure based on the applications in all the product classes (primary and secondary) assigned to the patent. The estimated coefficient using as the dependent variable the number of applications in the primary product class assigned 
to the patent is 0.378 (std. err. $=0.635)$. The sign of the coefficient suggests a positive effect of invalidation on follow on innovation, but the estimate is not statistically significant. As we discussed above, measures based on primary and extended sets are likely to be subject to countervailing measurement errors. The differences in magnitude, and statistical insignificance using the measure based on products in the primary class, suggest that this measure may substantially under-count the extent of cumulative innovation (and thus be subject to attenuation bias).

\subsection{Drugs}

\section{Data Construction}

In our sample 167 patent cases involve drug patents (patents belonging to the NBER category 3 but not in the sub-categories of Medical Instruments and Biotechnology). As an alternative to citations, in this technology field we measure cumulative innovation by identifying the subsequent clinical trials that are related to each Federal Circuit patent. To this end, we match each patent to the trade name of a drug, recover information on the active ingredients of the drug, and collect data on clinical trials that refer to the active ingredients.

Our data source for clinical trials is the website ClinicalTrials.gov, which is a registry database of publicly and privately supported clinical studies of human participants. ClinicalTrials.gov was created as a result of the Food and Drug Administration Modernization Act of 1997 that required the U.S. Department of Health and Human Services to establish a registry of clinical trials information. The site was made available to the public in 2000 and only reports clinical trials from 2000 onwards. Therefore, in order to have at least two years of post-litigation clinical trials data for each patent, most of our analysis will focus on patents litigated after 1997 (140 patent cases).

For each of the Federal Circuit drug patent in our sample, we identified the trade name of the drug protected by the patent. Such information was obtained from a multiplicity of sources: the text of the court decision, the FDA Orange Book (Approved Drug Products with Therapeutic Equivalence Evaluations) and specialized web-sites (in particular, DrugPatentWatch.com). We were able to match a patent with a drug for 94 patent cases, about 68 percent of our post-1997 sample. Cases in which the drug was not identified mostly involved patents related to DNA recombination, gene expressions and methods for conducting clinical tests. For 
the cases in which we were not able to match a patent with a specific drug, we collected up to three keywords describing the technology, after careful reading of the patent title and abstract.

For all these matched drugs, we identify the active ingredients. Also in this case the information was obtained from a multiplicity of sources: the text of the court decision, the Orange Book and specialized web-sites (especially from DrugPatentWatch.com or the Merck Index Online). Only 10 of the 94 patents have multiple active ingredients. Finally, for each of the matched patents, we obtained information on the clinical trials related to the active ingredient conducted in the five years following the Federal Circuit decision. The information was obtained from a text search in ClinicalTrials.gov with the active ingredient as keyword. In the case of multiple active ingredients, we search for each ingredient separately and measure clinical trials as the sum of trials involving any of the ingredients.

The average number of clinical trials in the five years that follow invalidation is 134.41 ( standard deviation $=125.76)$. The correlation between citations received in the five years after the Federal Circuit decision and clinical trials is 0.15 , and 0.18 in the subsample of drugs with only one active ingredient.

\section{Results}

Column 2 in Panel A of Table 9 in the paper shows the invalidation effect using the number of trials as the dependent variable. This column focuses only of the sample of matched drugs, those for which we identified a trade name associated with the patent. Results are consistent with those obtained using the patent citation measure. The coefficient is positive but statistically insignificant and its magnitude is very similar.

In column 3 we enlarge the sample including unmatched patents. The number of clinical trials for these patents is equal to the number of trials referring both to the primary and secondary keywords of the patent. The coefficient remains insignificant and its magnitude is slightly higher than the one in the previous columns. If we measure clinical trials for unmatched drugs by counting the clinical trials, referring only to the primary keyword, the estimated coefficient is 0.364 (standard error $=1.128$ ) and also in this case the estimate is statistically insignificant. 


\section{Substitute Patents: Data Construction}

We define a U.S. patent as related to the litigated patent if it has been granted before the decision date and it appears in the top ten related patent documents listed by Google. We collect a maximum of five related patents for each patent litigated at the Federal Circuit. The Google algorithm identified at least one related patent for 699 Federal Circuit decisions (about 52 percent of our sample). About 27 percent of these observations have only one matched related patent, 20 percent have two related patents and 53 percent have three or more related patents. For the Federal Circuit patents for which we were able to find at least one match, we first confirm that the estimated causal effect of invalidation on citations is similar to the one obtained in the full sample. Specifically, the IV coefficient is 0.541 (std. error $=0.257$ ), implying an increase in citations of approximately 70 percent.

We then re-estimated the baseline model but using as the dependent variable the citations to the related patents. In doing this, we experiment with a variety of alternative samples (e.g., balanced samples with top four or five related patents, as well as unbalanced samples where we keep all of the related patents identified by Google). All the regressions show a negative relationship between the post-decision citations to related patents and the invalidation of the focal patent, providing some support for the substitution hypothesis. Nonetheless, the estimates tend to be small and often statistically insignificant, confirming that the substitution hypothesis cannot explain much of the increase in citation caused by Federal Circuit invalidation. 


\section{References}

[1] Dolmeage, Brianna (2006), "The evolution of patentable subject matter in the United States," Whittier Law Review, 27: 1023-1045

[2] Feddersen, Timothy and Wolfgang Pesendorfer (1996) "The Swing Voter Curse," American Economic Review, 86: 408-424

[3] Golden, John (2009), "The Supreme Court as "Prime Percolator": A Prescription for Appellate Review of Questions in Patent Law," UCLA Law Review, 56: 657-724

[4] Hall, Bronwyn, Adam Jaffe and Manuel Tratjenberg (2001) "The NBER Patent Citation Data File: Lessons, Insights and Methodological Tools," NBER Working Paper 8498

[5] Kappos David, John Thomas and Randall Bluestone (2008), "A Technological contribution requirement for patentable subject matter: Supreme Court Precedent and Policy," Northwestern Journal of Technology and Intellectual Property, 6: 152-170 
Table A1. Federal Circuit Judges

\begin{tabular}{|c|c|c|c|}
\hline Judge & Active Service & $\begin{array}{c}\text { Validity Decisions 1982- } \\
2008\end{array}$ & $\begin{array}{c}\text { Percentage of Decisions in } \\
\text { which the Judge voted for } \\
\text { Invalidation }\end{array}$ \\
\hline Randall Ray Rader & 1990- & 242 & 39.6 \\
\hline Daniel Mortimer Friedman & 1982-1989 & 112 & 21.2 \\
\hline Pauline Newman & 1984- & 309 & 26.9 \\
\hline Glenn Leroy Archer, Jr. & 1985-1997 & 170 & 34.7 \\
\hline Haldane Robert Mayer & 1987-2010 & 269 & 42.4 \\
\hline S. Jay Plager & 1989-2000 & 153 & 35.3 \\
\hline Alan David Lourie & $1990-$ & 293 & 46.8 \\
\hline Raymond Charles Clevenger III & 1990-2006 & 232 & 37.9 \\
\hline Alvin Anthony Schall & 1992-2009 & 248 & 37.5 \\
\hline William Curtis Bryson & 1994- & 238 & 44.1 \\
\hline Arthur J. Gajarsa & 1997-2011 & 164 & 41.5 \\
\hline Richard Linn & 1999- & 111 & 43.2 \\
\hline Timothy B. Dyk & $2000-$ & 131 & 37.4 \\
\hline Sharon Prost & 2001- & 106 & 40.6 \\
\hline Kimberly Ann Moore & $2006-$ & 21 & 76.2 \\
\hline Giles Sutherland Rich & 1982-1999 & 152 & 40.8 \\
\hline Arnold Wilson Cowen & $1982-2007$ & 59 & 33.9 \\
\hline Oscar Hirsh Davis & $1982-1988$ & 70 & 50.1 \\
\hline Philip Nichols, Jr. & $1982-1990$ & 38 & 26.3 \\
\hline Byron George Skelton & 1982-2004 & 56 & 33.9 \\
\hline Phillip Benjamin Baldwin & $1982-1991$ & 54 & 25.9 \\
\hline Howard Thomas Markey & 1982-1991 & 138 & 49.3 \\
\hline Marion Tinsley Bennett & 1982-2000 & 57 & 57.9 \\
\hline Shiro Kashiwa & $1982-1986$ & 34 & 38.2 \\
\hline Jack Richard Miller & $1982-1994$ & 35 & 42.9 \\
\hline Edward Samuel Smith & $1982-2001$ & 91 & 36.3 \\
\hline Paul Redmond Michel & 1988-2010 & 245 & 41.6 \\
\hline Helen Wilson Nies & 1982-1996 & 89 & 38.2 \\
\hline Jean Galloway Bissell & 1984-1990 & 41 & 24.4 \\
\hline
\end{tabular}


TABLE A2. Exogeneity of Judge Panels (OLS Regressions)

\begin{tabular}{|c|c|c|c|c|c|c|c|}
\hline & 1 & 2 & 3 & 4 & 5 & 6 & 7 \\
\hline Depentend Variable & JIP & JIP & JIP & JIP & JIP & JIP & JIP \\
\hline $\log$ (Claims) & $\begin{array}{l}-0.001 \\
(0.002)\end{array}$ & & & & & $\begin{array}{l}-0.001 \\
(0.002)\end{array}$ & $\begin{array}{l}-0.001 \\
(0.002)\end{array}$ \\
\hline $\log$ (PreCites) & & $\begin{array}{l}-0.001 \\
(0.002)\end{array}$ & & & & $\begin{array}{c}0.001 \\
(0.002)\end{array}$ & $\begin{array}{c}0.001 \\
(0.002)\end{array}$ \\
\hline $\log ($ PreSelfCites) & & & $\begin{array}{l}-0.001 \\
(0.002)\end{array}$ & & & $\begin{array}{l}-0.001 \\
(0.002)\end{array}$ & $\begin{array}{l}-0.001 \\
(0.002)\end{array}$ \\
\hline Age & & & & $\begin{array}{c}-0.001 \\
(0.001)\end{array}$ & & $\begin{array}{c}-0.001 \\
(0.001)\end{array}$ & \\
\hline Chemicals & & & & & $\begin{array}{c}0.003 \\
(0.006)\end{array}$ & $\begin{array}{c}0.003 \\
(0.006)\end{array}$ & $\begin{array}{c}0.003 \\
(0.006)\end{array}$ \\
\hline Computers and Communication & & & & & $\begin{array}{l}-0.007 \\
(0.006)\end{array}$ & $\begin{array}{l}-0.007 \\
(0.006)\end{array}$ & $\begin{array}{l}-0.008 \\
(0.006)\end{array}$ \\
\hline Drugs and Medical & & & & & $\begin{array}{c}0.004 \\
(0.005)\end{array}$ & $\begin{array}{c}0.004 \\
(0.005)\end{array}$ & $\begin{array}{c}0.004 \\
(0.005)\end{array}$ \\
\hline Electrical and Electronics & & & & & $\begin{array}{c}0.005 \\
(0.006)\end{array}$ & $\begin{array}{c}0.005 \\
(0.006)\end{array}$ & $\begin{array}{c}0.006 \\
(0.006)\end{array}$ \\
\hline Mechanicals & & & & & $\begin{array}{c}0.007 \\
(0.007)\end{array}$ & $\begin{array}{c}0.007 \\
(0.007)\end{array}$ & $\begin{array}{c}0.007 \\
(0.007)\end{array}$ \\
\hline Year Effects & YES $* * *$ & YES*** & YES*** & YES $* * *$ & YES $* * *$ & YES $* * *$ & YES*** \\
\hline Age Effects & NO & NO & NO & NO & NO & NO & YES \\
\hline Fed. Circuit Decisions & 1357 & 1357 & 1357 & 1357 & 1357 & 1357 & 1357 \\
\hline $\begin{array}{l}\text { F-stat for all patent } \\
\text { characteristics (except year } \\
\text { dummies) being zero }\end{array}$ & & & & & $\begin{array}{l}F=1.00 \\
p=0.41\end{array}$ & $\begin{array}{l}F=0.67 \\
p=0.73\end{array}$ & $\begin{array}{l}F=0.77 \\
p=0.82\end{array}$ \\
\hline \multicolumn{8}{|c|}{$\begin{array}{l}\text { NOTES: }{ }^{*} \text { significant at } 10 \text { percent, }{ }^{* *} \text { significant at } 5 \text { percent and }{ }^{* * *} \text { significant at } 1 \text { percent. Robust standard errors } \\
\text { are reported in parentheses. Invalidated }=1 \text { if Federal Circuit invalidates at least one claim of focal patent. PreCites }= \\
\text { cites from patents of other assignees received before Federal Circuit decision. PreSelfCites }=\text { cites received from } \\
\text { patents owned by same patentee of focal patent before Federal Circuit decision. Claims }=\text { total number of claims } \\
\text { listed in focal patent. Age }=\text { age in years from filing date of patent at Federal Circuit decision. Year= year of Federal } \\
\text { Circuit Decision. JIP= propensity to vote for patent invalidity of judge panel constructed from invalidity votes of judges } \\
\text { in other sample cases. We add one to all citation measures to include patents with zero cites. }\end{array}$} \\
\hline
\end{tabular}


Table A3. Impact of Invalidation on Citations - Robustness (IV Regressions)

\begin{tabular}{|c|c|c|c|c|c|c|}
\hline & 1 & 2 & 3 & 4 & 5 & 6 \\
\hline Dependent Variable & $\log ($ PostCites) & $\log$ (PostCites) & $\log ($ PostCites) & $\log ($ PostCites) & $\begin{array}{c}\log \text { (PostCites) } \\
\text { Truncation- } \\
\text { Adjusted }\end{array}$ & $\begin{array}{c}\log (\text { PostCites) } \\
\text { Domestic } \\
\text { Citations }\end{array}$ \\
\hline Invalidated & $\begin{array}{c}0.394 * * \\
(0.197)\end{array}$ & $\begin{array}{c}0.915^{* *} \\
(0.422)\end{array}$ & $\begin{array}{l}0.392 * * \\
(0.180)\end{array}$ & $\begin{array}{c}0.484 * * \\
(0.214)\end{array}$ & $\begin{array}{c}0.473 * * \\
(0.201)\end{array}$ & $\begin{array}{c}0.529 * * * \\
(0.206)\end{array}$ \\
\hline
\end{tabular}

Refined (2-digit)

Tech dummies

YES***

Tech $x$ Year Effects

YES***

Sample

Drop Supreme Court Appeals

Full

Full

Decisions up to

$1345 \quad 1357$

1357

2003

Full

Full

Fed. Circuit Decisions

$1357-1357$

1001

1357

1357

NOTES: * significant at 10 percent, ${ }^{* *}$ significant at 5 percent and ${ }^{* * *}$ significant at 1 percent. Robust standard errors are reported in parentheses. All regressions control for $\log ($ PreCites), $\log ($ PreSelfCites) $\log ($ Claims $)$, age and year effects. PostCites = cites from patents of other assignees in 5 year window after Federal Circuit decision. Invalidated=1 if Federal Circuit invalidates at least one claim of focal patent. Technology field effects use 6 categories in columns 1 and 32 subcategories in column 2 (for details see Hall et al. 2001). We add one to all citation measures to include patents with zero cites. 
Table A4. Intensive and Extensive Margins - Robustness (IV Estimates)

\begin{tabular}{|c|c|c|c|c|c|c|}
\hline \multirow[t]{3}{*}{ Dependent Variable } & \multicolumn{3}{|c|}{$\begin{array}{c}\text { Total Effect } \\
\text { log(PostCites) }\end{array}$} & \multicolumn{3}{|c|}{$\begin{array}{c}\text { Extensive Margin } \\
\log (\text { Number of Distinct Assignees) }\end{array}$} \\
\hline & 1 & 2 & 3 & 4 & 5 & 6 \\
\hline & $\begin{array}{l}\text { Citing Patents in } \\
\text { Small Portfolios } \\
\text { (<5 patents) }\end{array}$ & $\begin{array}{l}\text { Citing Patents in } \\
\text { Small Portfolios } \\
\text { (<2 patents) }\end{array}$ & $\begin{array}{l}\text { Citing Patents in } \\
\text { Small Portfolios } \\
\text { (<2 patents) }\end{array}$ & $\begin{array}{l}\text { Citing Patents in } \\
\text { Small Portfolios } \\
\text { (<5 patents) }\end{array}$ & $\begin{array}{l}\text { Citing Patents in } \\
\text { Small Portfolios } \\
\text { (<2 patents) }\end{array}$ & $\begin{array}{c}\text { Citing Patents in } \\
\text { Small Portfolios } \\
\text { (<2 patents) }\end{array}$ \\
\hline Invalidated & $\begin{array}{c}0.046 \\
(0.179)\end{array}$ & $\begin{array}{c}0.125 \\
(0.168)\end{array}$ & $\begin{array}{c}0.128 \\
(0.165)\end{array}$ & $\begin{array}{c}0.015 \\
(0.152)\end{array}$ & $\begin{array}{c}0.076 \\
(0.143)\end{array}$ & $\begin{array}{c}0.088 \\
(0.141)\end{array}$ \\
\hline \multicolumn{7}{|l|}{ Invalidated X Large } \\
\hline Patentee (> 75 patents) & $\begin{array}{l}2.552^{* *} \\
(1.360)\end{array}$ & & $\begin{array}{l}2.248^{*} \\
(1.277)\end{array}$ & $\begin{array}{l}1.842 * * \\
(0.951)\end{array}$ & & $\begin{array}{l}1.390 * \\
(0.745)\end{array}$ \\
\hline Invalidated X Large & & & & & & \\
\hline Patentee (> 102 patents) & & $\begin{array}{l}1.769 * * \\
(0.752)\end{array}$ & & & $\begin{array}{l}1.216^{* *} \\
(0.550)\end{array}$ & \\
\hline
\end{tabular}

NOTES: ${ }^{*}$ significant at 10 percent, ${ }^{* *}$ significant at 5 percent and ${ }^{* * *}$ significant at 1 percent. Robust standard errors are reported in parentheses. All regressions control for $\log$ (PreCites) in the size group, $\log$ (PreSelfCites), $\log (\mathrm{Claims})$, age and year effects. PostCites = cites from patents of other assignees in 5 year window after Federal Circuit decision. Invalidated=1 if Federal Circuit invalidates at least one claim of focal patent. Invalidated and its interactions are instrumented by the Probit estimates of the probability of invalidation and its interactions. We add one to all citations measures to include patents with zero cites. 
Figure A1. Age Distribution of Litigated Patents

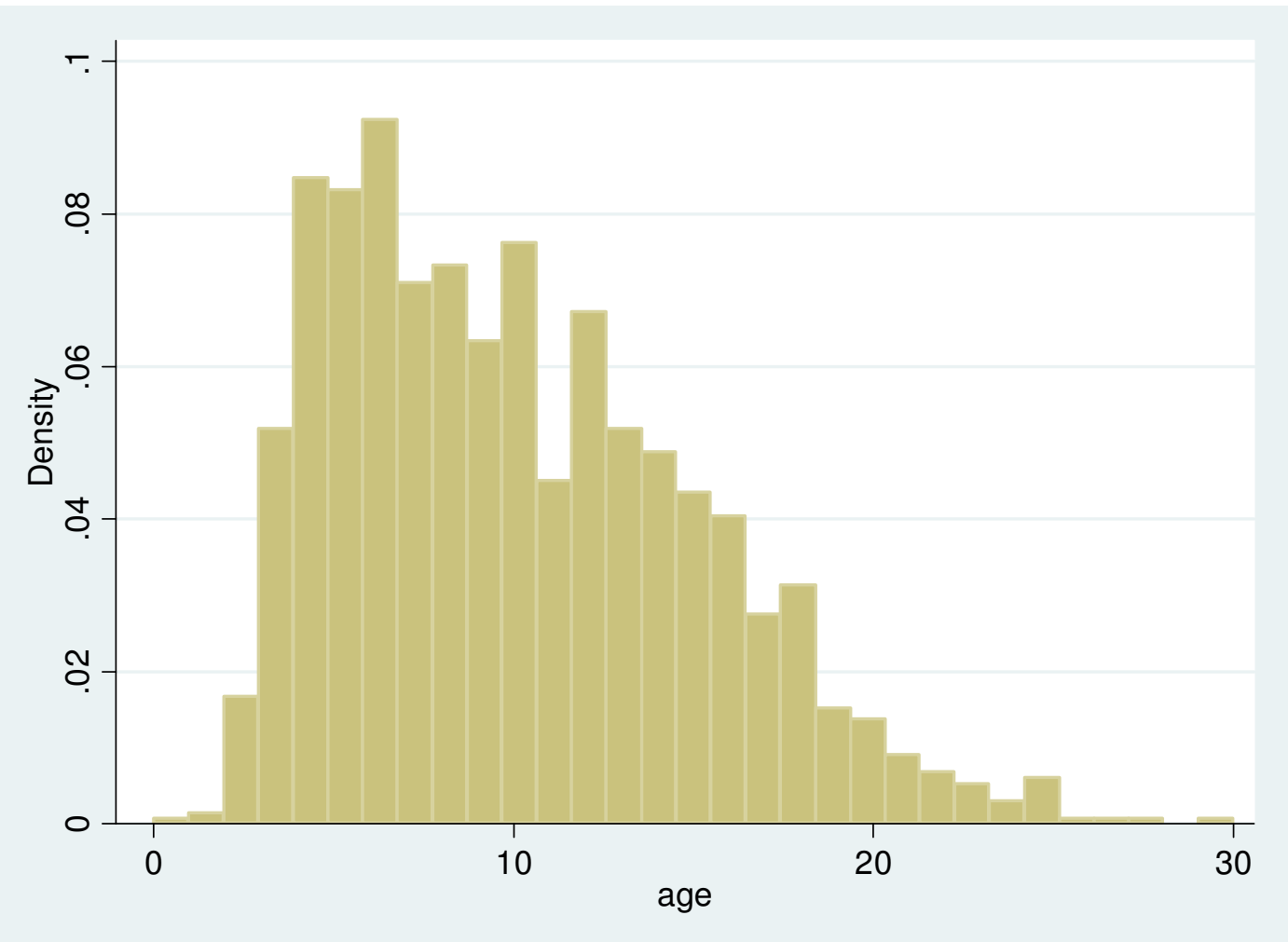


Figure A2. Simulated and Estimated Judge Fixed Effects

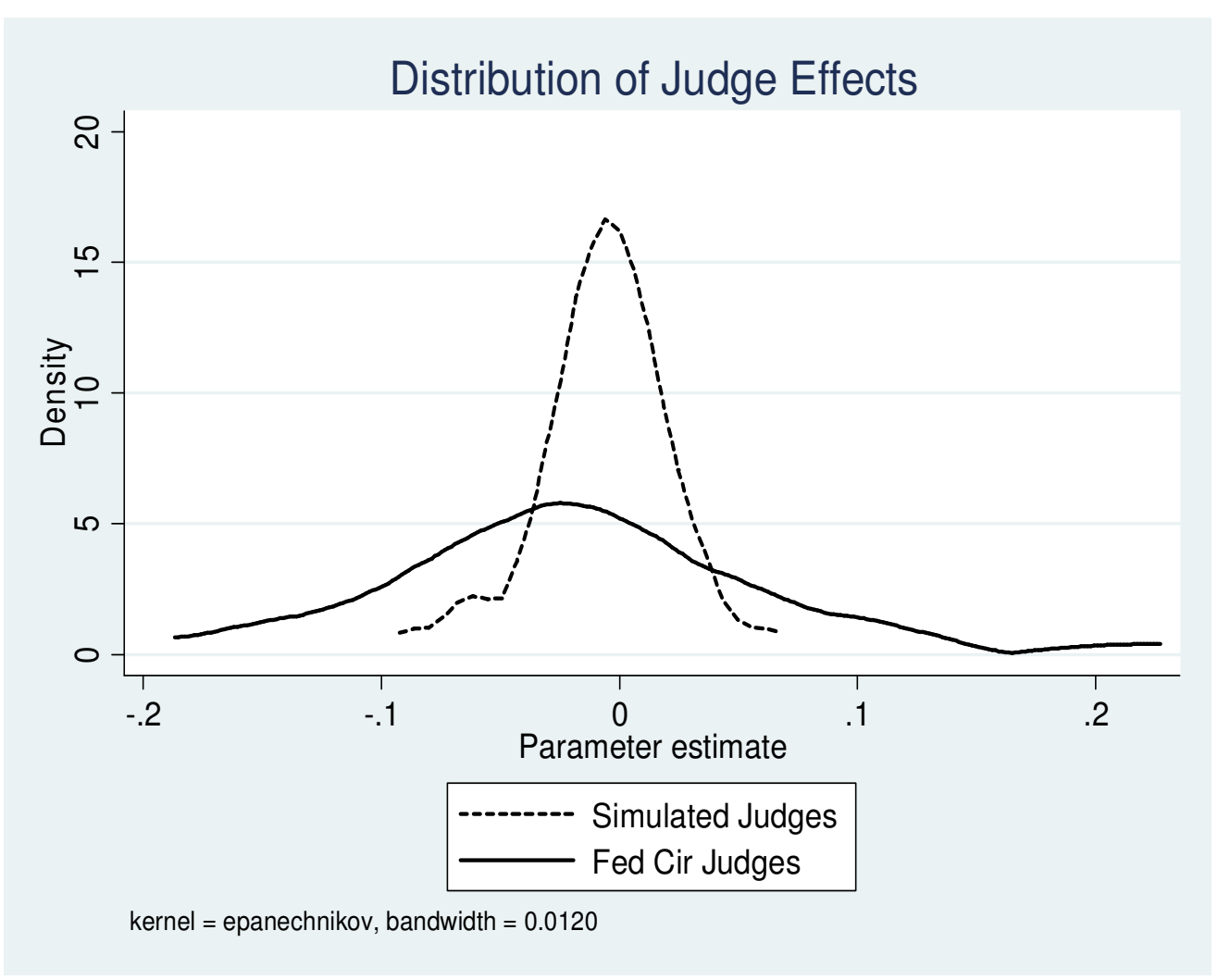

NOTES: The Figures compares the distribution of judges fixed effects in our data (solid line) with the distribution obtained from a simulation in which each judge votes with the same random process. 